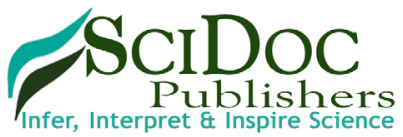

\author{
International Journal of Medical Biotechnology \& Genetics (IJMBG) \\ ISSN:2379-1020
}

\title{
Application of Synthetic Low Molecular Weight Heterocyclic Compounds Derivatives of Pyrimidine, Pyrazole and Oxazole in Agricultural Biotechnology as a New Plant Growth Regulating Substances
}

Research Article

Tsygankova $\mathrm{VA}^{1 *}$, Andrusevich $\mathrm{YaV}^{1}$, Shtompel OI ${ }^{1}$, Romaniuk OV ${ }^{2}$, Yaikova MYu², Hurenko AO ${ }^{1}$, Solomyanny RM ${ }^{1}$, Abdurakhmanova ER ${ }^{1}$, Klyuchko SV ${ }^{1}$, Holovchenko OV ${ }^{1}$, Bondarenko $\mathrm{OM}^{1}$, Brovarets $\mathrm{VS}^{1}$

Department for Chemistry of Bioactive Nitrogen-Containing Heterocyclic Compounds, Institute of Bioorganic Chemistry and Petrochemistry, National Academy of Sciences of Ukraine, Kyiv, Ukraine.

${ }^{2}$ Faculty of Biotechnology and Biotechnics, National Technical University of Ukraine "Igor Sikorsky Kyiv Polytechnic Institute", Kyiv, Ukraine.

\section{Abstract}

Study of plant growth regulating activity of synthetic low molecular weight heterocyclic compounds derivatives of pyrimidine, pyrazole, and oxazole was conducted. It was found that all tested synthetic heterocyclic compounds used at concentration $10^{-9} \mathrm{M} / 1$ of distilled water revealed high stimulating auxin-like activity on vegetative growth of two cultivars of pea and maize, and stimulating cytokinin-like activity on growth of the isolated cotyledons of pumpkin. The obtained biometric indexes of $21^{\text {st }}$-day-old seedlings of pea (Pisum sativum L.) of cultivar L35/11 middle stalwart bewhiskered grown on the water solution of heterocyclic compounds used at concentration $10^{-9} \mathrm{M} / 1$ of distilled water were higher of the biometric indexes of $21^{\text {st }}$-day-old seedlings of pea grown either on the distilled water (control) or on the water solution of auxins IAA and NAA used at the same concentration $10^{-9} \mathrm{M} / 1$ of distilled water in average: at the 7-8\% - by total length of seedlings, at the 6-46\% - by total length of roots, and at the $15-70 \%$ - by total number of roots. The obtained biometric indexes of $21^{\text {st }}$-day-old seedlings of pea (Pisum sativum L.) of cultivar L303/04 semi-dwarf bewhiskered grown on the water solution of heterocyclic compounds used at concentration $10^{-9} \mathrm{M} / 1$ of distilled water were higher of the biometric indexes of $21^{\text {st }}$-day-old seedlings of pea grown either on the distilled water (control) or on the water solution of auxins IAA and NAA used at the same concentration $10^{-9} \mathrm{M} / 1$ of distilled water in average: at the $18-23 \%$ - by total length of seedlings, at the $15-76 \%$ - by total length of roots, and at the $16-116 \%$ - by total number of roots. The obtained biometric indexes of $14^{\text {th }}$-day-old seedlings of maize (Zea mays L.) hybrid Palmyra FAO 190 grown on the water solution of heterocyclic compounds used at concentration $10^{-9} \mathrm{M} / 1$ of distilled water were higher of the biometric indexes of $21^{\text {st }}$-day-old seedlings of maize grown either on the distilled water (control) or on the water solution of auxins IAA and NAA used at the same concentration $10^{-9} \mathrm{M} / 1$ of distilled water in average: at the $23 \%$ by total length of seedlings, $5-37 \%$ - by total length of roots, and at the 7-87\% - by total number of roots. The specific bioassay on cytokinin-like activity conducted on the $16^{\text {th }}$-day-old cotyledons isolated from seeds of muscat pumpkin (Cucurbita moschata Duch. et Poir.) of cultivar Gilea, showed that all heterocyclic compounds derivatives of pyrimidine, pyrazole, and oxazole used at concentration $10^{-9} \mathrm{M} / 1$ of distilled water demonstrated high stimulating cytokinin-like activity. The indexes of biomass growth of isolated cotyledons of pumpkin grown on the water solution of heterocyclic compounds used at concentration $10^{-9} \mathrm{M} / 1$ of distilled water were higher of the indexes of biomass growth of isolated cotyledons of pumpkin grown either on the distilled water (control) or on the water solution of phytohormone cytokinin Kinetin used at the same concentration $10^{-9} \mathrm{M} / 1$ of distilled water in average at the $6-30 \%$. It was shown also the positive effect of some from tested synthetic heterocyclic compounds derivatives of pyrimidine, pyrazole, and oxazole on activation of photosynthetic processes in the leaves of $21^{\text {st }}$-day-old pea seedlings and $14^{\text {th }}$-day-old maize seedlings due to increase of synthesis of photosynthetic pigments in the plant cells; the content of chlorophyll a was increased in average at the 4-36\%; the content of chlorophyll $b$ was increased in average at the $3-74 \%$; the content of chlorophylls $a+b$ was increased in average at the $5-36 \%$; the chlorophylls a/b ratio was increased in average at the 3-44\%; the content of carotenoids was increased in average at the $3-37 \%$ as compared with control, IAA and NAA, respectively; the carotenoid/chlorophyll ratio was increased in average at the $7-17 \%$ as compared with control. The application in agricultural biotechnology of synthetic low molecular weight heterocyclic compounds derivatives of pyrimidine, pyrazole, and oxazole as new effective substitutes of phytohormones auxins and cytokinins for improving of cultivation of pea, maize, and pumpkinis is proposed.

Keywords: Agricultural Biotechnology; Pisum Sativum L.; Zea Mays L.; Cucurbita Moschata Duch. et Poir.; Auxins IAA and NAA; Cytokinin Kinetin; Plant Growth Regulating Substances; Synthetic Low Molecular Weight Heterocyclic Compounds; Pyrimidine; Pyrazole, Oxazole.

\section{*Corresponding Author:}

Victoria Anatolyivna Tsygankova ScD,

Department for Chemistry of Bioactive Nitrogen-Containing Heterocyclic Compounds, Institute of Bioorganic Chemistry and Petrochemistry, National Academy of Sciences of Ukraine, 1, Murmanskaya Str., Kyiv, 02660,Ukraine.

E-mail: vTsygankova@ukr.net

Received: February 10, 2017

Accepted: March 14, 2017

Published: March 22, 2017

Citation: Tsygankova VA, Andrusevich YaV, Shtompel OI, Romaniuk OV, Yaikova MYu, et al., (2017) Application of Synthetic Low Molecular Weight Heterocyclic Compounds Derivatives of Pyrimidine, Pyrazole and Oxazole in Agricultural Biotechnology as a New Plant Growth Regulating Substances. Int J Med Biotechnol Genetics S2:002, 10-32. doi: http://dx.doi.org/10.19070/2379-1020-SI02002

Copyright: Tsygankova VA ${ }^{\circ}$ 2017. This is an open-access article distributed under the terms of the Creative Commons Attribution License, which permits unrestricted use, distribution and reproduction in any medium, provided the original author and source are credited. 


\section{Introduction}

It is known that plant growth is the result of the different processes such as cell division, cell elongation, cell proliferation and cell differentiation resulting in formation of tissue, organ and whole plant organism; these basic processes are controlled by genetic program of plant growth and development [1-5]. The major classes of low molecular weight compounds such as phytohormones: auxins, cytokinins, gibberellins, abscisic acid, ethylene, brassinosteroids, jasmonates and salicylic acid play an a key role in the regulation of genetic program of plant growth and development during ontogenesis, improving of yield and product quality and increase of plant resistance to abiotic and biotic stress-factors (such as cold, drought, salinity, soil pollution by anthropogenic factors, and various pathogens and pests) [4, 6-17].

Plant hormones auxins (AUXs) are the major plant hormones involved in control of plant embryogenesis, promotion of seed germination, cell elongation and cell division in hypocotyls and coleoptiles, apical dominance, cambium cell division, plant tropisms, root initiation and development of root system on the plant seedlings as well as on the stem and leaf cuttings, promotion of fruit setting, prevention of leaf abscission, plant-pathogen interactions, and plant adaptation to biotic and abiotic stresses [18-29].

Plant hormones cytokinins (CKs) take an important part in control of embryo patterning, promotion of seed germination, deetiolation, cell cycle, protein synthesis, chloroplast differentiation, overcoming of apical dominance, releasing of lateral buds from dormancy, flower and fruit development, leaf senescence delaying, synthesis in the cotyledons of seeds of storage proteins and lipids that are essential for the further development of seedlings, plant-pathogen interactions and plant adaptation to biotic and abiotic stresses [26, 29-32].

Plant hormones gibberellic acids (GAs) play an a major role in control of plant embryogenesis, promotion of seed germination, stem and root elongation, leaf expansion, trichome development, meristematic tissue development, differentiation of floral organs, anther development, pollen maturation, seed and pericarp growth, plant adaptation to the environment [26, 33-38].

Plant hormone abscisic acid (ABA) takes an important part in control of formation of embryo, dormancy of embryo, seed and seed coat, bud growth, lateral root growth, synthesis of storage proteins and lipids in the cotyledons of seeds, prevention of premature seed germination, abscission of leaves, flowers and fruits, plant tolerance to drought, salt, hypoxic, cold stress, and wound or pathogen response, establishment of desiccation tolerance during seed dehydration and maturation, chlorophyll degradation, accumulation of pigments anthocyanes in the dehydrated seeds, stomata closure during water or osmotic stresses [26, 39-43].

Plant hormone ethylene (ET) plays an important role in regulation of many aspects of plant development ranging from germination to senescence via control of the basic processes of growth including cell division, cell elongation, cell differentiation and cell death [26, 43-48]. This plant hormone is involved in inhibition of the primary and lateral root elongation, and in contrast, stimulation of root hair development, inhibition of hypocotyl growth in the darkness, and in contrast, stimulation of elongation of the hypocotyl on the light, horizontal growth of stem with respect to gravity (i.e., diageotropism), stimulation of radial swelling of stem, swelling of hypocotyl and exaggerated hook curvature in etiolated (dark grown) seedlings [43-48]. Ethylene has a positive effect on fruit ripening, loss of chlorophyll, and abortion of plant parts, stems shortening, emergence and epinasty of leaves, promotes leaves abscission in autumn, and senescence at the end of a plant's life [47, 48]. Ethylene production is strongly regulated by internal signals during plant development; this plant hormone controls plant adaptive properties in response to environmental stimuli, both biotic and abiotic [43-48].

Plant hormones brassinosteroids (BRs) are involved in regulation of cell division, cell expansion, cell differentiation, programmed cell death, and cell homeostasis [26, 49-58]. These plant hormones reveal pleiotropic effects on varied physiological processes like photomorphogenesis and scotomorphogenesis (etiolation), promotion of elongation of hypocotyl, epicotyl, and mesocotyl in plant seedlings, seed germination, stem and root growth, gravitropism, xylem differentiation, vascular development, leaf morphogenesis, leaf bending and epinasty, photosynthesis, stomata development, leaf senescence and abscission, floral initiation, development of flowers, pollen tube growth, male fertility, development of fruits, plant adaptive properties in response to environmental stimuli, both biotic and abiotic [49-58].

Plant hormone jasmonic acid (JA) and its derivatives collectively referred to as jasmonates play an important role in plant growth and development during ontogenesis. These plant hormones reveal inhibitory effect on the germination of nondormant seeds, elongation of the coleoptile and main root axis, and in contrast, stimulating effect on various physiological processes like germination of dormant seeds, the formation and development of plant reproductive and vegetative organs such as flowers, pollen, fruit, seed, leaves, formation and elongation of the lateral and adventitious roots, formation of glandular trichomes, fruit ripening, synthesis of vegetative storage protein (VSPs) in seeds and pigments carotenoids in fruit, leaf senescence, stomata closure, biosynthesis of plant secondary metabolites that are important compounds for application in agricultural biotechnology and medicine, as well as plant adaptation to abiotic stress factors, such as water deficit, heat, cold, drought, salinity, light, and nutrient deficiency, and plant defense response to biotic stress factors such as viruses, bacteria, fungi, parasitic nematodes, herbivores [26, 58-62].

Plant hormone salicylic acid (SA) plays a vital role in the regulation of the basic processes of plant growthand development, including seed germination and seedling establishment, flowering, fruit ripening, stomatal aperture, respiration, leaf photosynthesis and senescence, under normal and under different abiotic stress conditions. SA takes part in plant tolerance to abiotic stress factors such as drought, salinity, heat, chilling, osmotic stress, heavy metal toxicity, and plant resistance to biotic stress factors such as pathogens and pests [26, 63-65].

Nowadays the different biotechnological and bioengineering tools based on traditional and molecular plant breeding methods, genetic engineering, cellular engineering, as well as chemical engineering methods based on application of different classes of phytohormones and plant growth regulators of synthetic or natural origin in the practice of sustainable agriculture to develop crops with genetically improved commercially important traits such 
as accelerated growth and development, increased productivity and quality, and enhanced resistance to a biotic and biotic stressfactors such as drought, salinity, cold, pathogenic and parasitic organisms, and soil pollution by anthropogenic factors [66-94].

The recent innovation strategy used in an agricultural biotechnology is the elaboration of new effective and ecologically safe plant growth regulating substances on the base of synthetic low molecular weight five and six-membered heterocyclic compounds derivatives of pyridine, pyrimidine, pyrazole, oxazole, and isoflavones as an effective substitutes of phytohormones and traditional growth regulators to improve growth of economically important agricultural crops and increase their productivity [95-110]. This innovation strategy is the most progressive approach to achieve successful development of modern agricultural biotechnology.

Pea (Pisum sativum L.) is an important agricultural crop cultivated over the world [111]. Cultivation of pea has beneficial impact on environment. Symbiosis of pea with nitrogen-fixing bacteria has positive influence on fixation of atmospheric nitrogen resulting in increased soil fertility; pea root system prevents erosion of the soil [112]. The rotation of peas with other crops results in decrease of pest outbreaks and prevents crop invasion by pests. Pea seed enriched with nutrients such as starch, protein, vitamins B and E, essential fatty acids omega-3 (alpha-linolenic acid, ALA) and omega-6 (linolenic acid, LA), carotenoids, polyphenolic antioxidants, minerals, soluble and insoluble dietary fiber, is used as source for human food and animal feed [113-115]. A garden pea (green pea) contains coumestrol and Bowman-Birk protease inhibitor (BBI) having protective effect against stomach cancer [116]. Pea seed contains a variety of bioactive substances including peptide fraction of total proteins having angiotensin I-converting enzyme inhibitor activity and antioxidant activity that play an important role for prevention of hypertension and ischemic heart disease; albumin fraction of total proteins having anti inflammatory effect on gastrointestinal tract; saponins exhibiting hypocholesterolemic and anticancer activity; galactose oligosaccharides exerting beneficial prebiotic effects in the large intestine; lectins, phytates, and phenolic compounds having important theraupeutic properties including modulation of detoxifying enzymes, stimulation of the immune system, regulation of lipid and hormone metabolism, antioxidant, antidiabetic, antimutagen, and antiangiogenic effects, reduction of tumor initiation and induction of apoptosis [114118]. Pea seed starch having lower glycaemic index due to intermediate amylose content positively effects on decrease of sucrose level in the blood due to which it can be used for prevention and treatment of diabetes [115]. The vitamins and minerals containing in pea seed play an important role for prevention of diseases, caused by deficiencies of Se or folate [114, 115]. Pea seed coat and the cell walls of the cotyledon are enriched with dietary fiber having therapeutic effect on gastrointestinal function, as well as polyphenolics and flavonoids proanthocyanidins (PAs) having antioxidant and anticarcinogenic activity $[114,115,119]$.

Maize (Zeamays L.) is ancient cereal crop traditionally used as source for dietary food and pharmaceutical industry due to high content of nutrients such as lipids, proteins, carbohydrates, vitamins, dietary fiber and biological active compounds in the seed and seed oil, and as raw material for the biofuel industry and animal feed [120-127].

Pumpkin (Cucurbita pepo L.) is widely cultivated crop used as source for dietary food, animal forage and drugs due to high content of biological active compounds in the fruit and seed oil such as carotenoids, flavonoid polyphenolic antioxidants, including lutein and xanthin, tocopherols, sterols, essential fatty acids omega-3 and omega- 6 , and vitamin A having antidiabetic, antifungal, antibacterial, antioxidant, anticancer, antihypertensive and anti-inflammatory activity [128-133].

The problem of increasing of pea, maize and pumpkin productivity, improving of quality of crop production and increase of crop resistance to abiotic and biotic stress-factors is quite relevant. Today the intensive technologies based on application of various classes phytohormones and plant growth regulators of natural and synthetic origin for improvement of growth and development of pea, maize and pumpkin are used in the practice of agricultural biotechnology [134-150]. The great theoretical and practical interest is the elaboration of new ecologically safe plant growth regulators created on the base of low molecular weight five and six-membered heterocyclic compounds having similar to phytohormones activity for improving of pea, maize and pumpkin growth and increase their productivity.

In our previous researches we showed that created at the Institute of Bioorganic Chemistry and Petrochemistry of National Academy of Sciences of Ukraine new synthetic low molecular weigh five and six-membered heterocyclic compounds derivatives of pyridine, pyrimidine, pyrazole, oxazole, and isoflavones revealed high stimulating, similar to phytohormones auxin and cytokinin activity on the growth and development of important agricultural crops such as flax, maize, haricot bean, pumpkins, soybean, wheat, and lettuce on both whole organism of plants in vivo and on the isolated plant tissues and organs in vitro conditions [151-154].

The aim of this work was study of growth regulating activity of new synthetic low molecular weight heterocyclic compounds derivatives of pyrimidine, pyrazole, and oxazole according to their stimulating effect on vegetative growth of pea and maize seedlings, and according to their cytokinin-like activity studied on the isolated cotyledons of pumpkin.

\section{Materials and Methods}

\section{Chemicals}

Plant growth regulating activity of synthetic low molecular weight five and six-membered heterocyclic compounds derivatives of pyrimidine (compounds № I-III), pyrazole (compounds № IV-VI), and phosphorylated derivatives of oxazole (compounds №VII and VIII) and pyrimidine (compounds №IX) was studied. The chemical low molecular weight five and six-membered heterocyclic compounds were synthesized at the Department for chemistry of bioactive nitrogen-containing heterocyclic compounds of Institute of Bioorganic Chemistry and Petrochemistry of NAS of Ukraine. The activity of chemical heterocyclic compounds was compared with the activity of phytohormones auxins IAA (compound №X) and NAA (compound №XI), and cytokinin Kinetin (compound № XII).

The chemical name, structure and relative molecular weight of phytohormones and synthetic heterocyclic compounds used for bioassays are shown on the Figure 1. 
Figure 1. Chemical Structures of Phytohormones and Synthetic Heterocyclic Compounds used for Bioassays.

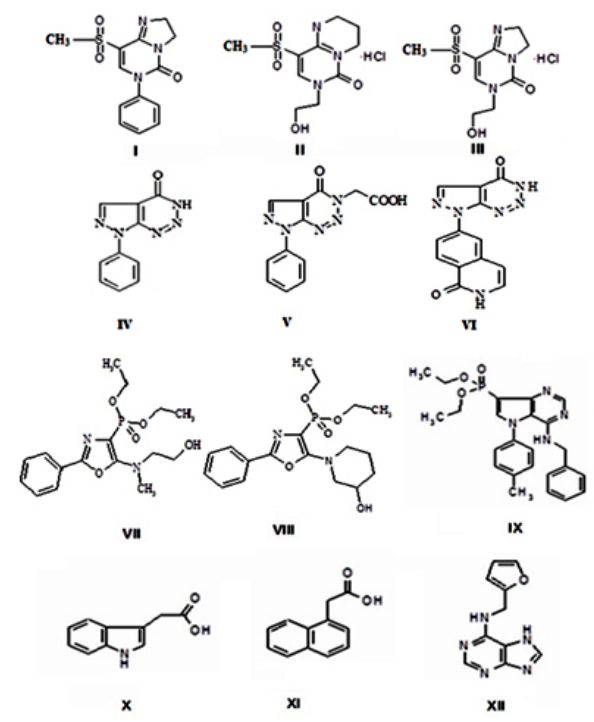

I. Compound 8-Methanesulfonyl-6-phenyl-2,6-dihydro-3Himidazo[1,2-c]pyrimidin-5-one, Molecular weight $=291,33$ $\mathrm{g} / \mathrm{mol}$

II. Compound 7-(2-Hydroxyethyl)-9-methanesulfonyl-2,3,4,7tetrahydropyrimido[1,6-a]pyrimidin-6-one hydrochloride, Molecular weight $=309,77 \mathrm{~g} / \mathrm{mol}$

III. Compound 6-(2-Hydroxyethyl)-8-methanesulfonyl-2,6dihydro-3H-imidazo[1,2-c]pyrimidine-5-one hydrochloride, Molecular weight $=295,74 \mathrm{~g} / \mathrm{mol}$

IV. Compound 7-(1,3-Benzothiazol-2-yl)-3H,4H,7Hpyrazolo[3,4-d] $[1,2,3]$ triazin-4-one, Molecular weight $=$ $270,27 \mathrm{~g} / \mathrm{mol}$

V. Compound 2-\{4-Oxo-7-phenyl-3H,4H,7H-pyrazolo[3,4-d] $[1,2,3]$ triazin-3-yl $\}$ acetic acid, Molecular weight $=271,24 \mathrm{~g} /$ mol

VI. Compound 6- $\{4-\mathrm{Oxo}-3 H, 4 H, 7 H$-pyrazolo[3,4-d][1,2,3] triazin-7-yl $\}$-1,2-dihydroisoquinolin-1-one, Molecular weight $=280,24 \mathrm{~g} / \mathrm{mol}$

VII. Compound Diethylester $\{5-[(2-$ Hydroxyethyl)-methylamino]-2-phenyl-1,3-oxazol-4-yl $\}$ phosphonic acid, Molecular weight $=354,338 \mathrm{~g} / \mathrm{mol}$

VIII.Compound Diethyl ester [5-(3-Hydroxypiperidin-1-yl)2-phenyl-1,3-oxazol-4-yl]phosphonic acid, Molecular weight $=380,375 \mathrm{~g} / \mathrm{mol}$

IX. Compound 4-Benzylamino-5-p-tolyl-5H-pyrrolo-[3,2-d pyrimidin-7-yl)phosphonic acid diethyl ester, Molecular weight $=450.48 \mathrm{~g} / \mathrm{mol}$

X. IAA (1H-Indol-3-ylacetic acid), Molecular weight $=175.19$ $\mathrm{g} / \mathrm{mol}$

XI. NAA (1-Naphthylacetic acid), Molecular weight $=186.21$ $\mathrm{g} / \mathrm{mol}$

XII. Kinetin (N-(2-Furylmethyl)-7H-purin-6-amine), Molecular weight $=215.22 \mathrm{~g} / \mathrm{mol}$

Study of growth regulating activity of synthetic heterocyclic compounds on pea and maize seedlings

In the laboratory conditions we studied growth regulating activity of phytohormones auxins IAA and NAA, and synthetic heterocyclic compounds derivatives of pyrimidine, pyrazole, and phosphorylated derivatives of oxazole and pyrimidine according to their impact on germination of seeds and vegetative growth of seedlings of two cultivars of pea (Pisum sativum L.) - of cultivar L35/11 middle stalwart bewhiskered and cultivar L303/04 semi-dwarf bewhiskered, as well as maize (Zea mays L.) hybrid Palmyra FAO 190. With this aim seeds of these crops were surface sterilized successively in $1 \% \mathrm{KMnO}_{4}$ solution for 3 min and $96 \%$ ethanol solution for $1 \mathrm{~min}$, and then washed three times with sterile distilled water. After this procedure seeds were placed in the cuvettes (each containing 25-30 seeds) on the perlite moistened with distilled water (control) or with water solution of each heterocyclic compound used at concentration $10^{-9} \mathrm{M} / 1$ of distilled water or water solution of auxins IAA or NAA used at the same concentration $10^{-9} \mathrm{M} / 1$ of distilled water (experiment). Control and experimental seeds were placed in the thermostat for their germination in the darkness at the temperature $23^{\circ} \mathrm{C}$ during 48 hours. Sprouted seedlings were placed in the plant growth chamber in which seedlings were grown for 21 days at the 16/8 $\mathrm{h}$ light/dark conditions, at the temperature $+24^{\circ} \mathrm{C}$, light intensity 3000 lux and air humidity $60-80 \%$. Comparative analysis of biometric indexes of seedlings (i.e. number of germinated seeds $(\%)$, seedlings height $(\mathrm{cm})$, root number (pcs), root length $(\mathrm{mm})$ ) was carried out at the $21^{\text {st }}$ day after their sprouting according to the guideline [155].

Study of cytokinin-like activity of synthetic heterocyclic compounds on the isolated cotyledons of pumpkin

The cytokinin-like activity of synthetic heterocyclic compounds derivatives of pyrimidine, pyrazole, and phosphorylated derivatives of oxazole and pyrimidine was studied using specific bioassay conducted on the cotyledons isolated from seeds of muscat pumpkin (Cucurbita moschata Duch. et Poir.) of cultivar Gilea [156, 157]. With this aim seeds of pumpkin were surface sterilized in $1 \% \mathrm{KMnO}_{4}$ solution for $3 \mathrm{~min}$ and $96 \%$ ethanol solution for 1 min and then washed three times with sterile distilled water. Sterilized seeds were placed in the cuvettes (each containing 20-25 seeds) on the filter paper moistened with distilled water. After this procedure seeds were placed in the thermostat for their germination in the darkness at the temperature $+25^{\circ} \mathrm{C}$ during 96 hours. The $4^{\text {th }}$-day-old pumpkin seedlings were separated from cotyle- 
dons using sterile scalpel. The isolated cotyledons were weighted and placed in the cuvettes (each containing 20 seeds) on the filter paper moistened with distilled water (control) or with water solution of heterocyclic compounds used at concentration $10^{-9} \mathrm{M} / 1$ of distilled water or with water solution of phytohormone cytokinin Kinetin used at the same concentration $10^{-9} \mathrm{M} / 1$ of distilled water (experiment). Control and experimental isolated cotyledons were placed in the plant growth chamber in which they were grown during 16 days at above mentioned conditions. To determine the index of growth of biomass $(\mathrm{g})$ of the isolated $16^{\text {th }}$-day-old cotyledons of pumpkin, they were washed with sterile distilled water and weighted at intervals every 4 days.

\section{Study impact of synthetic heterocyclic compounds on the total content of pigments in the leaves of plants}

To evaluate impact of synthetic heterocyclic compounds derivatives of pyrimidine, pyrazole, and phosphorylated derivatives of oxazole and pyrimidine on total content of chlorophylls and carotenoids in plant material we used leaves isolated from the middle and upper tiers of pea and maize seedlings. To perform extraction of pigments the samples $(0.5 \mathrm{~g})$ of leaves were weighed and homogenized in the porcelain mortar in a cooled $96 \%$ ethanol at a ratio of 1:10 (weight:volume) with addition of $0.1-0.2 \mathrm{~g}$ $\mathrm{CaCO}_{3}$ (to neutralize the plant acids). The obtained homogenates at a volume $10 \mathrm{ml}$ were centrifuged during $15 \mathrm{~min}$ at $8000 \mathrm{~g}$ and at the temperature $+4^{\circ} \mathrm{C}$ in the centrifuge, type K24D (MLW, Engelsdorf, Germany). The obtained precipitates were washed three times with 1-3 $\mathrm{ml} \mathrm{96 \%} \mathrm{etanol} \mathrm{and} \mathrm{centrifuged} \mathrm{at} \mathrm{above} \mathrm{mentioned}$ conditions. After this procedure we performed spectrophotometric analysis of chlorophyll a, chlorophyll $b$ and carotenoid in the obtained extract using a spectrophotometer Specord M40 (Carl Zeiss, Germany).

The calculation of total content of chlorophyll a, chlorophyll b, and carotenoids was performed using the following formula [158]:

$\mathrm{C}_{\mathrm{chla}}=13.36 \times \mathrm{A} 664.2-5.19 \times \mathrm{A} 648.6$,

$\mathrm{C}_{\text {chl b }}^{\text {chl }}=27.43 \times \mathrm{A} 648.6-8.12 \mathrm{~A} \times 664.2$,

$\mathrm{C}_{\mathrm{chl}}(\mathrm{a}+\mathrm{b})=5.24 \times \mathrm{A} 664.2+22.24 \times \mathrm{A} 648.6$,

$\mathrm{C}_{\mathrm{car}}=\left(1000 \times \mathrm{A} 470-2.13 \times \mathrm{C}_{\mathrm{chl} \mathrm{a}}-97.64 \times \mathrm{C}_{\mathrm{chlb}}\right) / 209$,

Where,

$\mathrm{C}_{\mathrm{chl}}$ - concentration of chlorophylls $(\mathrm{mg} / \mathrm{ml})$,

$\mathrm{C}_{\mathrm{car}}$ - concentration of carotenoids $(\mathrm{mg} / \mathrm{ml})$,

$\mathrm{C}_{\mathrm{chl}}$ - concentration of chlorophyll a $(\mathrm{mg} / \mathrm{ml})$,

$\mathrm{C}_{\mathrm{chl} \mathrm{b}}$ - concentration of chlorophyll b $(\mathrm{mg} / \mathrm{ml})$,

$\mathrm{A}-$ absorbance value at a proper wavelength in $\mathrm{nm}$.

The chlorophyll content per $1 \mathrm{~g}$ of fresh weight (FW) of plant tissue extracted was calculated by the following formula (separately for chlorophyll a and chlorophyll b):

$A_{1}=(C \times V) /\left(1000 \times a_{1}\right)$

Where,

$\mathrm{A}_{1}$ - content of chlorophyll a or chlorophyll b (mg/g FW),

$\mathrm{C}$ - concentration of pigments $(\mathrm{mg} / \mathrm{ml})$,

$\mathrm{V}$ - volume of extract $(\mathrm{ml})$,

$\mathrm{a}_{1}$ - sample of plant material (g).

\section{Statistical Analysis}

Each experiment was performed in triplicate. Statistical analysis of the data was performed using dispersive Student's-t test with the level of significance at $\mathrm{P} \leq 0.05$, the values are mean \pm SD [159].

\section{Results}

Stimulating effect of chemical heterocyclic compounds derivatives of pyrimidine on vegetative growth of pea (Pisum sativum $\mathrm{L}$.) of cultivar L35/11 middle stalwart bewhiskered

In the laboratory conditions we studied growth regulating activity of synthetic heterocyclic compounds derivatives of pyrimidine used at concentration $10^{-9} \mathrm{M} / 1$ of distilled water on seed germination and vegetative growth of pea (Pisum sativum L.) of cultivar L35/11 middle stalwart bewhiskered (Figure 2).

The growth regulating activity of synthetic heterocyclic compounds was compared with the activity of phytohormones auxins IAA and NAA used at the same concentration $10^{-9} \mathrm{M} / 1$ of distilled water. The obtained results showed that all tested heterocyclic compounds revealed high stimulating effect on growth of the

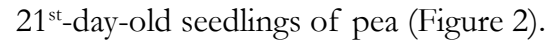

It was found that all synthetic heterocyclic compounds considerably stimulated growth and development of roots on the $21^{\text {st }}$ day-old pea seedlings, and their stimulating effect was similar or higher than the effect of phytohormones auxins IAA and NAA (Figure 3).

The comparative analysis of biometric indexes of $21^{\text {st }}$-day-old seedlings of pea (i.e. number of germinated seeds (\%), length of seedlings $(\mathrm{cm})$, total number of roots (pcs), total length of roots $(\mathrm{mm})$ ) showed that the biometric indexes of pea seedlings grown on the water solution of chemical heterocyclic compounds derivatives of pyrimidine used at concentration $10^{-9} \mathrm{M} / 1$ of distilled water were as generally similar or higher than the biometric indexes of $21^{\text {st }}$-day-old pea seedlings grown on the water solution of phytohormones auxins IAA and NAA used at the same concentration $10^{-9} \mathrm{M} / 1$ of distilled water as compared to lower biometric indexes of $21^{\text {st }}$-day-old pea seedlings grown on the distilled water (control) (Figure 4).

Particularly, it was found that the highest growth regulating activity revealed the compound № III - 6-(2-Hydroxyethyl)-8-methanesulfonyl-2,6-dihydro-3H-imidazo[1,2-c]pyrimidine-5-one hydrochloride; the biometric indexes of $21^{\text {st }}$-day-old pea seedlings grown on the water solution of this compound used at concentration $10^{-9} \mathrm{M} / 1$ of distilled water were as generally higher than the biometric indexes of $21^{\text {st }}$-day-old pea seedlings grown either on the distilled water (control) or on the water solution of auxins IAA and NAA used at the same concentration $10^{-9} \mathrm{M} / 1$ of distilled water as follows: according with length of seedlings - at the $7 \%$ as compared with control; according with total length of roots at the $46 \%, 15 \%$, and $15 \%$ as compared with control, IAA and NAA, respectively; according with total number of roots - at the $70 \%, 54 \%$ and $48 \%$ as compared with control, IAA and NAA, respectively (Figure 4). 
Figure 2. Impact of synthetic heterocyclic compounds derivatives of pyrimidine and phytohormones auxins IAA and NAA on vegetative growth of the $21^{\text {st }}$-day-old seedlings of pea (Pisum sativum $\mathrm{L}$.) of cultivar L35/11 middle stalwart bewhiskered. C - Control (distilled water), IAA - Compound $1 H$-Indol-3-ylacetic acid, NAA - Compound 1-Naphthylacetic acid, Compound № I - 8-Methanesulfonyl-6-phenyl-2,6-dihydro-3H-imidazo[1,2-c]pyrimidin-5-one, Compound № II

-7-(2-Hydroxyethyl)-9-methanesulfonyl-2,3,4,7-tetrahydropyrimido[1,6-a]pyrimidin-6-one hydrochloride, Compound № III - 6-(2-Hydroxyethyl)-8-methanesulfonyl-2,6-dihydro-3H-imidazo[1,2-c]pyrimidine-5-one hydrochloride.

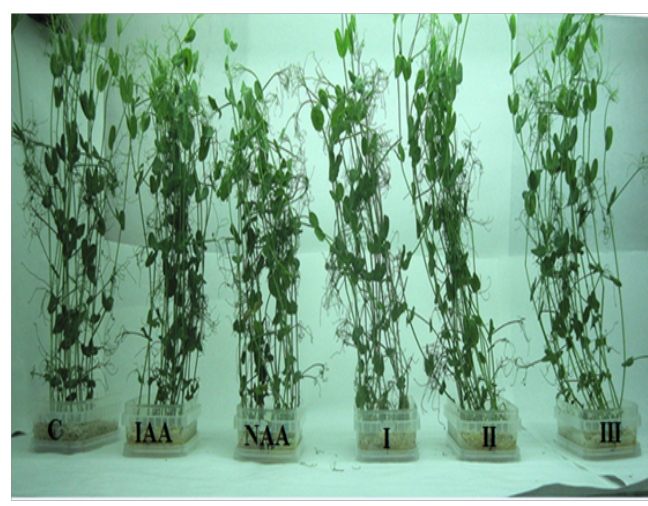

Figure 3. Impact of synthetic heterocyclic compounds derivatives of pyrimidine and phytohormones auxins IAA and NAA on growth of roots on the $21^{\text {st }}$-day-old seedlings of pea (Pisum sativum L.) of cultivar L35/11 middle stalwart bewhiskered. C - Control (distilled water), IAA - Compound $1 H$-Indol-3-ylacetic acid, NAA - Compound 1-Naphthylacetic acid, Compound №I - 8-Methanesulfonyl-6-phenyl-2,6-dihydro-3H-imidazo[1,2-c]pyrimidin-5-one, Compound №II -7-(2-Hydroxyethyl)-9-methanesulfonyl-2,3,4,7-tetrahydropyrimido[1,6-a]pyrimidin-6-one hydrochloride, Compound № III - 6-(2-Hydroxyethyl)-8-methanesulfonyl-2,6-dihydro-3H-imidazo[1,2-c]pyrimidine-5-one hydrochloride.

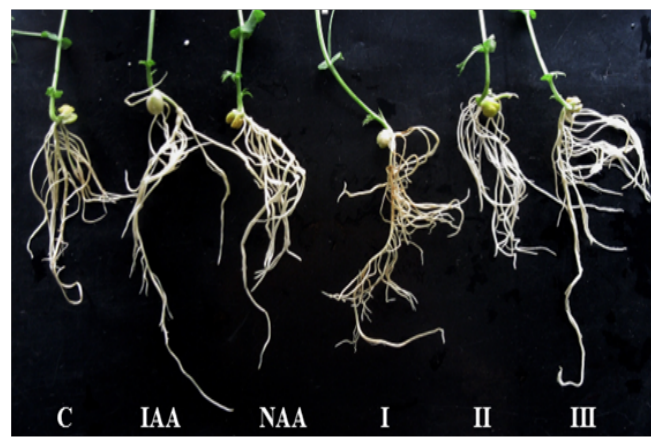

Figure 4. Impact of synthetic heterocyclic compounds derivatives of pyrimidine and phytohormones auxins IAA and NAA on biometric indexes of the $21^{\text {st }}$-day-old seedlings of pea (Pisum sativum L.) of cultivar L35/11 middle stalwart bewhiskered. Control (distilled water), IAA - Compound $1 H$-Indol-3-ylacetic acid, NAA - Compound 1-Naphthylacetic acid, Compound №I - 8-Methanesulfonyl-6-phenyl-2,6-dihydro-3H-imidazo[1,2-c]pyrimidin-5-one, Compound №II -7-(2-Hydroxyethyl)-9-methanesulfonyl-2,3,4,7-tetrahydropyrimido[1,6-a]pyrimidin-6-one hydrochloride, Compound № III - 6-(2-Hydroxyethyl)-8-methanesulfonyl-2,6-dihydro-3H-imidazo[1,2- $c$ ]pyrimidine-5-one hydrochloride. A - Number of germinated seeds $(\%), \mathrm{B}$ - length of seedlings $(\mathrm{cm}), \mathrm{C}$ - total length of roots $(\mathrm{mm})$, D - total number of roots (pcs).

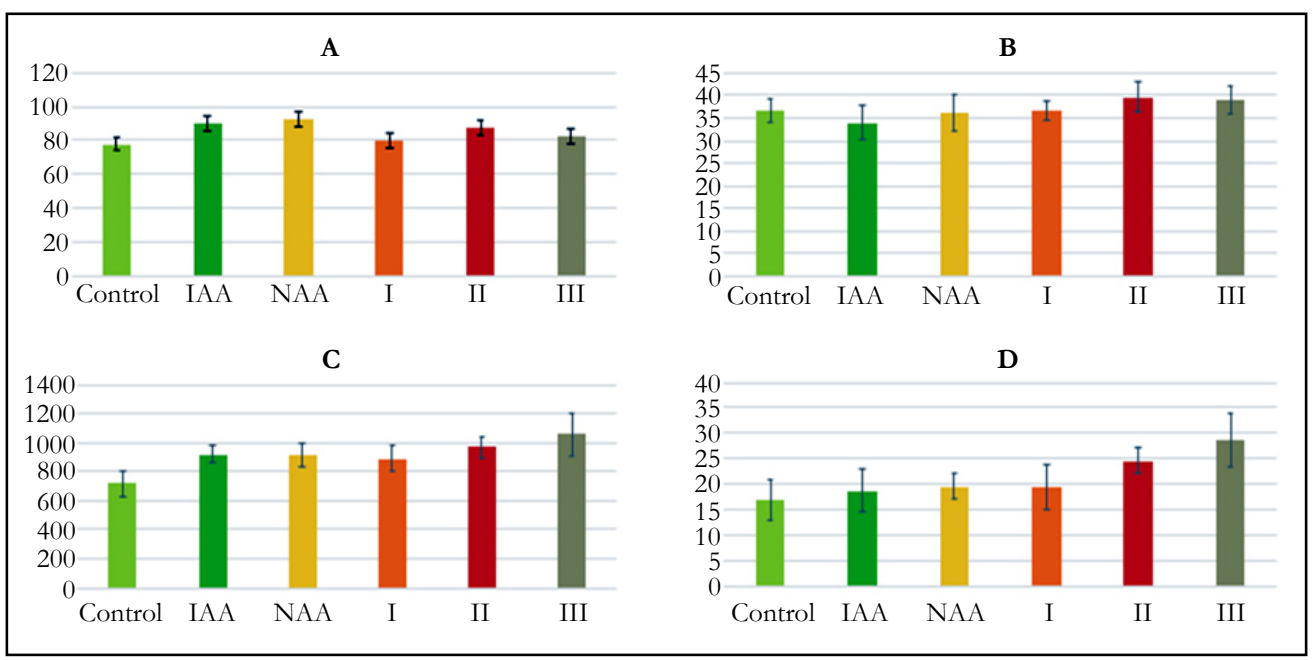


The high growth regulating activity revealed also the compound № II -7-(2-Hydroxyethyl)-9-methanesulfonyl-2,3,4,7tetrahydropyrimido[1,6-a]pyrimidin-6-one hydrochloride; the biometric indexes of $21^{\text {st }}$-day-old pea seedlings grown on the water solution of this compound used at concentration $10^{-9} \mathrm{M} / 1$ of distilled water were as generally higher than the biometric indexes of $21^{\text {st }}$-day-old pea seedlings grown either on the distilled water (control) or on the water solution of auxins IAA and NAA used at the same concentration $10^{-9} \mathrm{M} / 1$ of distilled water as follows: according with length of seedlings - at the $8 \%$ as compared with control; according with total length of roots - at the $35 \%, 6 \%$, and $6 \%$ as compared with control, IAA and NAA, respectively; according with total number of roots - at the $46 \%, 32 \%$ and $27 \%$ as compared with control, IAA and NAA, respectively (Figure 4).

The lower growth regulating activity revealed the compound №I - 8-Methanesulfonyl-6-phenyl-2,6-dihydro-3H-imidazo[1,2-c]pyrimidin-5-one; the biometric indexes of $21^{\text {st }}$-day-old pea seedlings grown on the water solution of this compound used at concentration $10^{-9} \mathrm{M} / 1$ of distilled water were as generally higher than the biometric indexes of $21^{\text {st }}$-day-old pea seedlings grown on the distilled water (control) as follows: according with total length of roots - at the $24 \%$ as compared with control, and according with total number of roots - at the $15 \%$ as compared with control (Figure 4).

Based on the obtained results it is possible to assume that the growth stimulating activity of synthetic heterocyclic compoundsderivatives of pyrimidine, which is similar to activity of phytohormones auxins, may be explained by their inducing effect on the plant cell division, cell elongation, cell proliferation, cell differentiation, and the increase of cell metabolism, resulting in an improving of growth and development of pea (Pisum sativum L.) of cultivar L35/11 middle stalwart bewhiskered.

Impact of synthetic heterocyclic compounds derivatives of pyrimidine on the total content of pigments in the leaves of pea (Pisum sativum L.) of cultivar L35/11 middle stalwart bewhiskered

It is known that photosynthesis is a key process that ensures the productivity of plants, so the study of quantitative and qualitative content of photosynthetic pigments and their ratio in the plant cells is a very important aspect to clarify the impact of plant growth regulating compounds on the productivity of plants [158, 160-162]. The important indicator of the balanced photosynthetic process is the ratio of chlorophylls $\mathrm{a} / \mathrm{b}$, since the chlorophyll $\mathrm{a}$ is bound to both photosynthetic reaction centers and light-harvesting complexes (LHCs) or antennas, while chlorophyll b and carotenoids are bound exclusively to light-harvesting complexes (LHCs) of a photosystem [158, 160-162]. Thus, changes in the chlorophylls $\mathrm{a} / \mathrm{b}$ ratiomay indicate the degree of formation of plant photosystem.

Carotenoids belong to major plant pigments that play an important role in photosynthetic processes in the plant cells and a positive role in human health [163-165]. It is known that there is significant correlation in carotenoid/chlorophyll ratio indices across various plant species growing in different natural environments; but usually this correlation is disrupted in senescing leaves during the seasonal changes [161].

In this work we conducted comparative study of impact of synthetic heterocyclic compounds derivatives of pyrimidine, and phytohormones auxins IAA and NAA used at concentration $10^{-}$ ${ }^{9} \mathrm{M} / 1$ of distilled water on the total content of chlorophylls (including chlorophyll a and chlorophyll b), as well as carotenoids in the leaves of $21^{\text {st }}$-day-old seedlings of pea (Pisum sativum L.) of cultivar L35/11 middle stalwart bewhiskered. The obtained results showed the increase of total content of pigments in the leaves of $21^{\text {st }}$-day-old pea seedlings grown on the water solution of some synthetic heterocyclic compounds used at concentration $10^{-9} \mathrm{M} / 1$ of distilled water (Figure 5 ).

The increase of synthesis of chlorophyll a was found in the cells of leaves of $21^{\text {st }}$-day-old pea seedlings grown on the water solution of compound № III - 6-(2-Hydroxyethyl)-8-methanesulfonyl-2,6-dihydro-3H-imidazo[1,2- $c]$ pyrimidine-5-one hydrochloride used at concentration $10^{-9} \mathrm{M} / 1$ of distilled water; the content of chlorophyll a was increased at the $19 \%, 36 \%$ and $22 \%$ as compared with control, IAA and NAA, respectively (Figure 5).

Similar changes were observed in the cells of leaves of $21^{\text {st }}$-day-

Figure 5. Impact of synthetic heterocyclic compounds derivatives of pyrimidine and phytohormones auxins IAA and NAA on the content of chlorophyll a, chlorophyll b, and carotenoids in the leaves of the $21^{\text {st }}$-day-old seedlings of pea (Pisum sativum L.) of cultivar L35/11 middle stalwart bewhiskered. Control (distilled water), IAA - Compound 1H-Indol-3-ylacetic acid, NAA - Compound 1-Naphthylacetic acid, Compound № I - 8-Methanesulfonyl-6-phenyl-2,6-dihydro-3H-imidazo[1,2c]pyrimidin-5-one, Compound № II -7-(2-Hydroxyethyl)-9-methanesulfonyl-2,3,4,7-tetrahydropyrimido[1,6-a]pyrimidin6-one hydrochloride, Compound № III - 6-(2-Hydroxyethyl)-8-methanesulfonyl-2,6-dihydro-3H-imidazo[1,2-c]pyrimidine5-one hydrochloride.

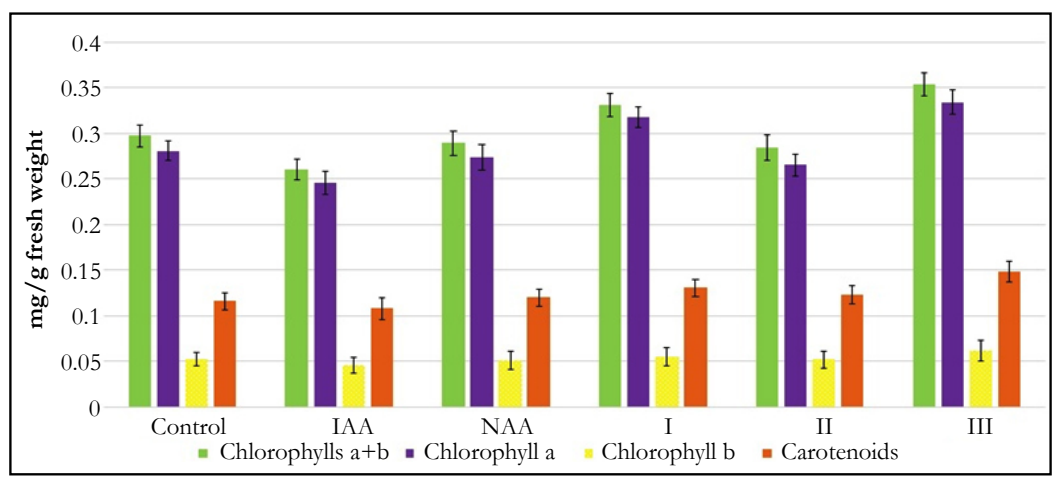


old pea seedlings grown on the water solution of compound № I - 8-Methanesulfonyl-6-phenyl-2,6-dihydro-3H-imidazo[1,2- $c$ ] pyrimidin-5-one; the content of chlorophyll a was increased at the $12 \%, 29 \%$ and $16 \%$ as compared with control, IAA and NAA, respectively (Figure 5).

A slight decline in synthesis of chlorophyll a was found in the cells of leaves of $21^{\text {st }}$-day-old pea seedlings grown on the water solution of compound № II -7-(2-Hydroxyethyl)-9-methanesulfonyl-2,3,4,7-tetrahydropyrimido[1,6-a]pyrimidin-6-one hydrochloride; the content of chlorophyll a was decreased at the $6 \%$ as compared with control, but at the same time its content was higher at the $8 \%$ as compared with IAA and similar to NAA, respectively (Figure 5).

Our studies showed also the increase of synthesis of chlorophyll $\mathrm{b}$ in the cells of leaves of $21^{\text {st }}$-day-old pea seedlings grown on the water solution of compound № III - 6-(2-Hydroxyethyl)-8-metha nesulfonyl-2,6-dihydro-3H-imidazo[1,2-c]pyrimidine-5-one hydrochloride used at concentration $10^{-9} \mathrm{M} / 1$ of distilled water; the content of chlorophyll b was increased at the $17 \%, 35 \%$ and $21 \%$ as compared with control, IAA and NAA, respectively (Figure 5).

The similar increase of synthesis of chlorophyll b was observed in the cells of leaves of $21^{\text {st }}$-day-old pea seedlings grown on the water solution of compound № I - 8-Methanesulfonyl-6-phenyl-2,6-dihydro-3H-imidazo[1,2-c]pyrimidin-5-one; the content of chlorophyll b was increased at the $6 \%, 21 \%$ and $9 \%$ as compared with control, IAA and NAA, respectively (Figure 5).

The increase of the content of chlorophyll b was shown also in the cells of leaves of $21^{\text {st }}$-day-old pea seedlings grown on the water solution of compound № II -7-(2-Hydroxyethyl)-9-metha nesulfonyl-2,3,4,7-tetrahydropyrimido[1,6-a]pyrimidin-6-one hydrochloride; the content of chlorophyll $b$ was increased at the $13 \%$ as compared with IAA (Figure 5).

It was found also the positive effect of compounds № I, № II and № III on increase of the content of total chlorophylls $a+b$ in the cells of leaves of $21^{\text {st }}$-day-old pea seedlings (Figure 5).

The highest content of chlorophylls $\mathrm{a}+\mathrm{b}$ was found in the cells of leaves of $21^{\text {st }}$-day-old pea seedlings grown on the water solution of compound № III - 6-(2-Hydroxyethyl)-8-methanesulfonyl-2,6-dihydro-3H-imidazo[1,2-c]pyrimidine-5-one hydrochloride - at the $19 \%, 36 \%$ and $22 \%$ as compared with control, IAA and NAA, respectively (Figure 5).

The high content of chlorophylls $\mathrm{a}+\mathrm{b}$ was observed in the cells of leaves of $21^{\text {st }}$-day-old pea seedlings grown on the water solution of compound № I - 8-Methanesulfonyl-6-phenyl-2,6-dihydro-3H-imidazo[1,2-c]pyrimidin-5-one - at the $11 \%, 27 \%$ and $15 \%$ as compared with control, IAA and NAA, respectively (Figure 5).

The content of chlorophylls $\mathrm{a}+\mathrm{b}$ was increased also in the cells of leaves of $21^{\text {st }}$-day-old pea seedlings grown on the water solution of compound № II -7-(2-Hydroxyethyl)-9-methanesulfonyl2,3,4,7-tetrahydropyrimido[1,6-a]pyrimidin-6-one hydrochloride at the $9 \%$ as compared with IAA (Figure 5).
It was found that the chlorophylls $\mathrm{a} / \mathrm{b}$ ratio in the cells of leaves of $21^{\text {st }}$-day-old pea seedlings grown on the water solution of compound №I used at concentration $10^{-9} \mathrm{M} / 1$ of distilled water was increased at the $8 \%, 7 \%, 7 \%$ as compared with control, IAA and NAA, respectively (Figure 5).

The similar increase of chlorophylls a/b ratio at the $2 \%$ as compared with control was observed in the cells of leaves of $21^{\text {st }}$-dayold pea seedlings grown on the water solution of compound № III used at concentration $10^{-9} \mathrm{M} / 1$ of distilled water (Figure 5).

The investigation of quantitative content of carotenoids showed the increase of content of carotenoids in the cells of leaves of $21^{\text {st }}$-day-old pea seedlings grown on the water solution of compound № III - 6-(2-Hydroxyethyl)-8-methanesulfonyl-2,6-dihydro-3H-imidazo[1,2-c]pyrimidine-5-one hydrochloride at the $28 \%, 37 \%$ and $24 \%$ as compared with control, IAA and NAA, respectively (Figure 5).

The increase of content of carotenoids was also observed in the cells of leaves of $21^{\text {st }}$-day-old pea seedlings grown on the water solution of compound №I - 8-Methanesulfonyl-6-phenyl-2,6dihydro-3H-imidazo[1,2- $c$ pyrimidin-5-one; the content of carotenoids in the cells of leaves of $21^{\text {st }}$-day-old pea seedlings grown on the water solution of compound № I was increased at the $12 \%, 21 \%$ and $9 \%$ as compared with control, IAA and NAA, respectively (Figure 5).

Similar changes were observed in the cells of leaves of $21^{\text {st }}$-dayold pea seedlings grown on the water solution of compound №II-7-(2-Hydroxyethyl)-9-methanesulfonyl-2,3,4,7-tetrahydropyrimido[1,6-a]pyrimidin-6-one hydrochloride; the content of carotenoids in the cells of leaves of $21^{\text {st }}$-day-old pea seedlings grown on the water solution of compound № II was increased at the $6 \%, 14 \%$ and $3 \%$ as compared with control, IAA and NAA, respectively (Figure 5).

The important aspect of our research was study impact of synthetic heterocyclic substances on correlation in carotenoid/chlorophyll ratio in the plant cells; the minor changes in the carotenoid/chlorophyll ratio was observed in the cells of leaves of $21^{\text {st }}$-day-old pea seedlings grown on the water solution of heterocyclic compounds № II and № III used at concentration $10^{-9} \mathrm{M} / 1$ of distilled water; the carotenoid/chlorophyll ratio was increased at the $10 \%$ and $8 \%$, respectively, as compared to control.

The similar changes in the balance of endogenous photosynthetic pigments was observed in the leaves of $21^{\text {st }}$-day-old pea seedlings grown on the water solution of auxins IAA and NAA used at concentration $10^{-9} \mathrm{M} / 1$ of distilled water; the carotenoid/chlorophyll ratio indices was increased at the $5 \%$ and $5 \%$, respectively, as compared to control.

The conducted researches confirmed impact of all tested synthetic heterocyclic compounds derivatives of pyrimidine and phytohormones auxins IAA and NAA on change of the balance of endogenous photosynthetic pigments in the leaves of $21^{\text {st }}$-day-old seedlings of pea (Pisum sativum L.) of cultivar L35/11 middle stalwart bewhiskered. 
Study of cytokinin-like activity of synthetic heterocyclic compounds derivatives of pyrimidine on the isolated cotyledons of muscat pumpkin (Cucurbita moschata Duch. et Poir.) of cultivar Gilea

The cytokinin-like growth regulating activity of synthetic heterocyclic compounds derivatives of pyrimidine was studied using the most known bioassay on growth of biomass of cotyledons (i.e. food-storage organs) isolated from seeds of pumpkin (Cucurbita pepo L.) [156, 157]. In our work we used as an experimental material the isolated cotyledons from seeds of muscat pumpkin (Cucurbita moschata Duch. et Poir.) of cultivar Gilea, which is an important agricultural crop.

It was shown that all tested compounds manifested the expressive cytokinin-like activity; the obtained indexes of growth of biomass of the isolated cotyledons of pumpkin incubated during 16 days on the water solution of some from tested synthetic heterocyclic compounds used at concentration $10^{-9} \mathrm{M} / 1$ of distilled water were similar or higher than the indexes of growth of biomass of isolated cotyledons of pumpkin incubated during 16 days on the water solution of phytohormone cytokinin Kinetin used at the same concentration $10^{-9} \mathrm{M} / 1$ of distilled water as compared with control (Figure 6).

Among the synthetic heterocyclic compounds the highest growth regulating activity revealed the compound № III-6-(2Hydroxyethyl)-8-methanesulfonyl-2,6-dihydro-3H-imidazo[1,2- $c$ ] pyrimidine-5-one hydrochloride; the indexes of growth of biomass of the isolated cotyledons of pumpkin grown on the water solution of compound № III used at concentration $10^{-9} \mathrm{M} / 1$ of distilled water were higher at the $28 \%$ and $10 \%$ than the indexes of growth of biomass of the isolated cotyledons of pumpkin grown either on the distilled water (control) or on the water solution of cytokinin Kinetin used at the same concentration $10^{-9} \mathrm{M} / 1$ of distilled water, respectively (Figure 6).
The high growth regulating activity demonstrated also compound № I- 8-Methanesulfonyl-6-phenyl-2,6-dihydro-3H-imidazo[1,2- $c$ ] pyrimidin-5-one; the indexes of growth of biomass of the isolated cotyledons of pumpkin grown on the water solution of compound № I used at concentration $10^{-9} \mathrm{M} / 1$ of distilled waterwere higher at the $18 \%$ than the indexes of growth of biomass of the isolated cotyledons of pumpkin grown on the distilled water (control) (Figure 6).

The lower growth regulating activity demonstrated compound № II -7-(2-Hydroxyethyl)-9-methanesulfonyl-2,3,4,7tetrahydropyrimido[1,6-a]pyrimidin-6-one hydrochloride; the indexes of growth of biomass of the isolated cotyledons of pumpkin grown on the water solution of compound № II used at concentration $10^{-9} \mathrm{M} / 1$ of distilled water were higher at the $13 \%$ than the indexes of growth of biomass of the isolated cotyledons of pumpkin grown on the distilled water (control) (Figure 6).

Thus, the obtained results confirmed high cytokinin-like growth regulating activity of synthetic heterocyclic compounds derivatives of pyrimidine, which was similar or higher of activity of phytohormone Kinetin. Obviously that growth regulating activity of synthetic heterocyclic compounds may be explained by their specific cytokinin-like inducing effect on cell division and cell elongation, as well as activation of biosynthetic processes in the cells of isolated cotyledons of muscat pumpkin (Cucurbita moschata Duch. et Poir.) of cultivar Gilea resulting in an increase of their growth and biomass.

Stimulating effect of synthetic heterocyclic compounds derivatives of pyrazole on vegetative growth of pea (Pisum sativum L.) of cultivar L303/04 semi-dwarf bewhiskered

In the laboratory conditions we studied growth regulating activity of synthetic heterocyclic compounds derivatives of pyrazole used at concentration $10^{-9} \mathrm{M} / 1$ of distilled water on seed germination and vegetative growth of pea (Pisum sativum L.) of cultivar L303/04 semi-dwarf bewhiskered (Figure 7). The growth regulat-

Figure 6. Impact of synthetic heterocyclic compounds derivatives of pyrimidine and phytohormone cytokinin Kinetin on growth of biomass of isolated cotyledons from seeds of muscat pumpkin (Cucurbita moschata Duch. et Poir.) of cultivar Gilea during the 16 days. Control (distilled water), Compound № I - 8-Methanesulfonyl-6-phenyl-2,6-dihydro-3Himidazo[1,2-c]pyrimidin-5-one, Compound № II -7-(2-Hydroxyethyl)-9-methanesulfonyl-2,3,4,7-tetrahydropyrimido[1,6-a] pyrimidin-6-one hydrochloride, Compound № III - 6-(2-Hydroxyethyl)-8-methanesulfonyl-2,6-dihydro-3H-imidazo[1,2- $c]$ pyrimidine-5-one hydrochloride.

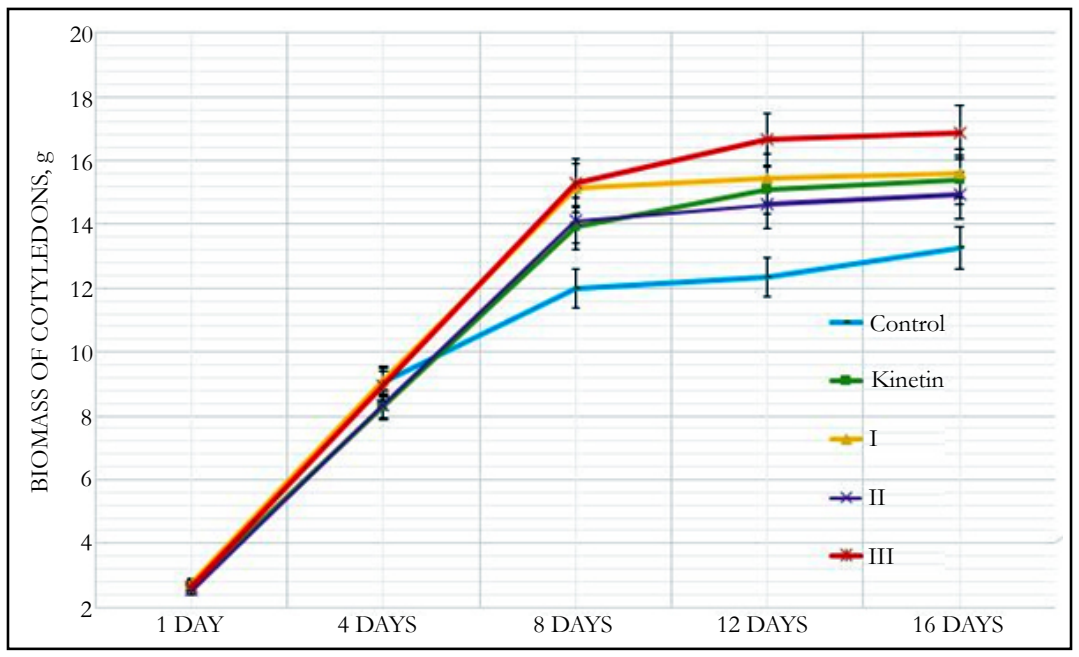


Figure 7. Impact of synthetic heterocyclic compounds derivatives of pyrazole and phytohormones auxins IAA and NAA on vegetative growth of the $21^{\text {st }}$-day-old seedlings of pea (Pisum sativum $\mathrm{L}$.) of cultivar L303/04 semi-dwarf bewhiskered. C - Control (distilled water), IAA - Compound $1 H$-Indol-3-ylacetic acid, NAA - Compound 1-Naphthylacetic acid, Compound NoIV - 7-(1,3-Benzothiazol-2-yl)-3H,4H,7 H-pyrazolo[3,4-d] [1,2,3] triazin-4-one, Compound №V -2-\{4-Oxo7-phenyl-3H,4H,7H-pyrazolo[3,4-d] [1,2,3]triazin-3-yl\}acetic acid, Compound №VI - 6-\{4-Oxo-3H,4H,7H-pyrazolo[3,4- $d]$ $[1,2,3]$ triazin-7-yl\}-1,2-dihydroisoquinolin-1-one.

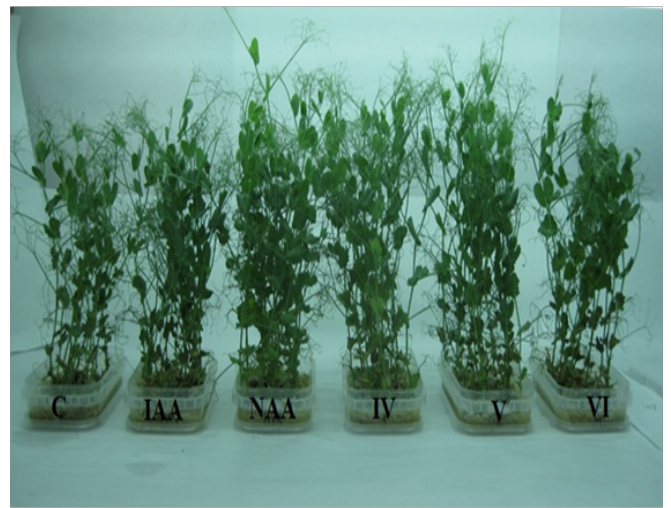

ing activity of synthetic heterocyclic compounds was compared with the activity of phytohormones auxins IAA and NAA that were used at the same concentration $10^{-9} \mathrm{M} / 1$ of distilled water.

The obtained results showed that all tested heterocyclic compounds revealed high stimulating effect on growth of the $21^{\text {st }}$ day-old seedlings of pea (Pisum sativum L.) of cultivar L303/04 semi-dwarf bewhiskered (Figure 7).

It was found also that all synthetic heterocyclic compounds considerably stimulated growth and development of roots on the $21^{\text {st }}$-day-old pea seedlings, and their stimulating effect was similar or higher than the effect of phytohormones auxins IAA and NAA (Figure 8).

The comparative analysis of biometric indexes of $21^{\text {st }}$-day-old seedlings of pea (i.e. number of germinated seeds (\%), length of seedlings $(\mathrm{cm})$, total number of roots (pcs), total length of roots $(\mathrm{mm})$ ) showed that the biometric indexes of pea seedlings grown on the water solution of chemical heterocyclic compounds derivatives of pyrazole used at concentration $10^{-9} \mathrm{M} / 1$ of distilled water were as generally similar or higher than the biometric indexes of $21^{\text {st }}$-day-old pea seedlings grown on the water solution of phytohormones auxins IAA and NAA used at the same concentration $10^{-9} \mathrm{M} / 1$ of distilled water as compared to lower biometric indexes of $21^{\text {st }}$-day-old pea seedlings grown on the distilled water (control) (Figure 9).

Particularly it was found that the highest growth regulating activity revealed the compound $\mathrm{NoV}-2-\{4-\mathrm{Oxo}-7$-phenyl-3H,4H,7Hpyrazolo[3,4- $d][1,2,3]$ triazin-3-yl $\}$ acetic acid; the biometric indexes of $21^{\text {st }}$-day-old pea seedlings grown on the water solution of this compound used at concentration $10^{-9} \mathrm{M} / 1$ of distilled waterwere as generally higher than the biometric indexes of $21^{\text {st }}$-dayold pea seedlings grown either on the distilled water (control) or on the water solution of auxins IAA and NAA used at the same concentration $10^{-9} \mathrm{M} / 1$ of distilled water as follows: according with length of seedlings - at the $23 \%$ as compared with control; according with total length of roots - at the $76 \%, 37 \%$ and $21 \%$ as compared with control, IAA and NAA, respectively; according with total number of roots - at the $116 \%, 64 \%$ and $49 \%$ as com- pared with control, IAA and NAA, respectively (Figure 9).

The lower growth regulating activity revealed the compound № IV-7-(1,3-Benzothiazol-2-yl)-3 H,4 H,7 H-pyrazolo[3,4- $d][1,2,3]$ triazin-4-one; the biometric indexes of $21^{\text {st }}$-day-old pea seedlings grown on the water solution of this compound used at concentration $10^{-9} \mathrm{M} / 1$ of distilled water were as generally higher than the biometric indexes of $21^{\text {st }}$-day-old pea seedlings grown on the distilled water (control) as follows: according with length of seedlings - at the $18 \%$ as compared with control; according with total length of roots - at the $15 \%$ as compared with control; according with total number of roots - at the $16 \%$ as compared with control (Figure 9).

The lower growth regulating activity revealed also the compound №VI - 6-\{4-Oxo-3H,4H,7H-pyrazolo[3,4- $d[1,2,3]$ triazin7-yl $\}$-1,2-dihydroisoquinolin-1-one; the biometric indexes of $21^{\text {st }}$-day-old pea seedlings grown on the water solution of this compound used at concentration $10^{-9} \mathrm{M} / 1$ of distilled water were as generally higher than the biometric indexes of $21^{\text {st }}$-day-old pea seedlings grown on the distilled water (control) as follows: according with total length of roots - at the $19 \%$ as compared with control, and according with total number of roots - at the $17 \%$ as compared with control (Figure 9).

Based on the obtained results it is possible to assume that high growth stimulating activity of synthetic heterocyclic compounds derivatives of pyrazole, which is similar to activity of phytohormones auxins, may be explained by their inducing effect on the plant cell division, cell elongation, cell proliferation, cell differentiation, and the increase of cell metabolism, resulting in an improving of growth and development of pea (Pisum sativum L.) of cultivar L303/04 semi-dwarf bewhiskered.

Impact of synthetic heterocyclic compounds derivatives of pyrazole on the total content of pigments in the leaves of pea (Pisum sativum L.) of cultivar L303/04 semi-dwarf bewhiskered

In our work we also studied impact of synthetic heterocyclic compounds derivatives of pyrazole used at concentration $10^{-9} \mathrm{M} / 1$ 
Figure 8. Impact of synthetic heterocyclic compounds derivatives of pyrazole and phytohormones auxins IAA and NAA on growth of roots on the $21^{\text {st }}$-day-old seedlings of pea (Pisum sativum L.) of cultivar L303/04 semi-dwarf bewhiskered. C - Control (distilled water), IAA - Compound $1 H$-Indol-3-ylacetic acid, NAA - Compound 1-Naphthylacetic acid, Compound NoIV - 7-(1,3-Benzothiazol-2-yl)-3H,4H,7 H-pyrazolo[3,4-d] [1,2,3] triazin-4-one, Compound №V -2-\{4-Oxo7-phenyl-3H,4H,7H-pyrazolo[3,4-d] [1,2,3]triazin-3-yl\}acetic acid, Compound №VI - 6-\{4-Oxo-3H,4H,7H-pyrazolo[3,4- $d]$ $[1,2,3]$ triazin-7-yl\}-1,2-dihydroisoquinolin-1-one.

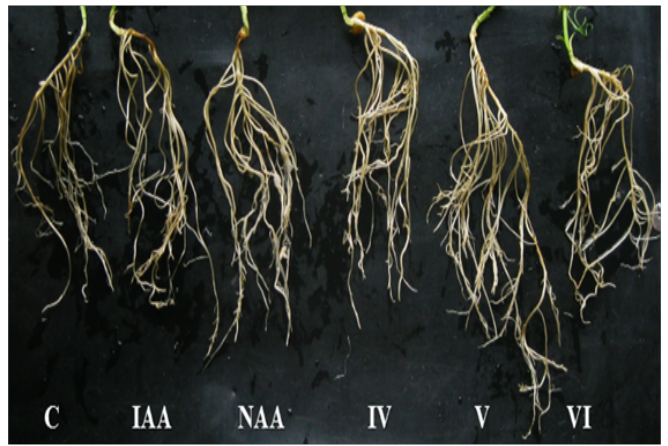

Figure 9. Impact of synthetic heterocyclic compounds derivatives of pyrazole and phytohormones auxins IAA and NAA on biometric indexes of the $21^{\text {st }}$-day-old seedlings of pea (Pisum sativum L.) of cultivar L303/04 semi-dwarf bewhiskered. Control (distilled water), IAA - Compound $1 H$-Indol-3-ylacetic acid, NAA - Compound 1-Naphthylacetic acid, Compound №IV - 7-(1,3-Benzothiazol-2-yl)-3H,4H,7 $H$-pyrazolo[3,4-d][1,2,3] triazin-4-one, Compound №V -2-\{4-Oxo-7-phenyl$3 H, 4 H, 7 H$-pyrazolo[3,4-d] [1,2,3] triazin-3-yl\}acetic acid, Compound №VI - 6-\{4-Oxo-3H,4H,7H-pyrazolo[3,4-d] [1,2,3] triazin-7-yl\}-1,2-dihydroisoquinolin-1-one. A - Number of germinated seeds (\%), B - length of seedlings (cm), C - total length of roots $(\mathrm{mm}), \mathrm{D}$ - total number of roots (pcs).

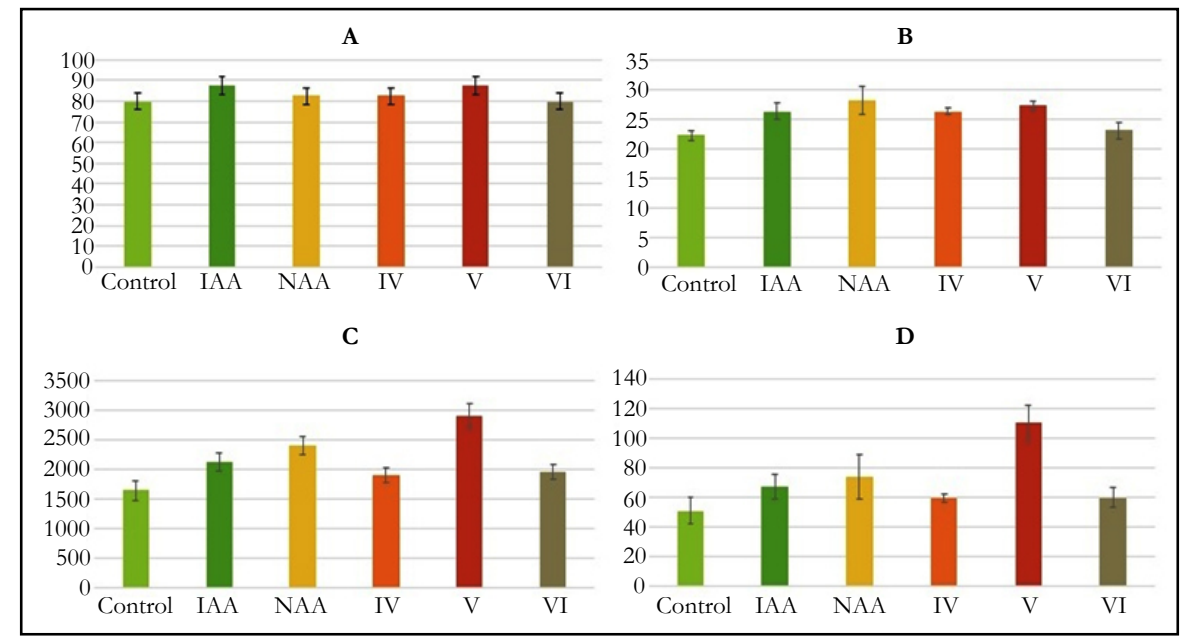

of distilled water on the total content of chlorophylls (including chlorophyll a and chlorophyll b), as well as carotenoids in the leaves of $21^{\text {st }}$-day-old seedlings of pea (Pisum sativum L.) of cultivar L303/04 semi-dwarf bewhiskered. The activity of synthetic heterocyclic compounds was compared with the activity of phytohormones auxins IAA and NAA that were used at the same concentration $10^{-9} \mathrm{M} / 1$ of distilled water.

The obtained results showed that some from tested heterocyclic compounds revealed high stimulating effect on increase of synthesis of pigments in the leaves of $21^{\text {st }}$-day-old pea seedlings grown on the water solution of some synthetic heterocyclic compounds (Figure 10).

The increase of synthesis of chlorophyll a was observed in the cells of leaves of $21^{\text {st }}$-day-old pea seedlings grown on the water solution of compound № IV-7-(1,3-Benzothiazol-2-yl)-3H,4H,7Hpyrazolo $[3,4-d][1,2,3]$ triazin-4-one used at concentration $10^{-9} \mathrm{M} / 1$ of distilled water; the content of chlorophyll a was increased at the $29 \%, 23 \%$ and $12 \%$ as compared with control, IAA and NAA, respectively (Figure 10).

Similar changes were observed in the cells of leaves of $21^{\text {st }}$-dayold pea seedlings grown on the water solution of compound №V -2-\{4-Oxo-7-phenyl-3H,4H,7H-pyrazolo[3,4-d][1,2,3]triazin3 -yl $\}$ acetic acid; the content of chlorophyll a was increased at the $8 \%$ and $4 \%$ as compared with control and IAA, respectively (Figure 10).

In contrast, the decrease of content of chlorophyll a at the $18 \%, 21 \%$ and $28 \%$ as compared with control, IAA and NAA, respectively, was observed in the cells of leaves of $21^{\text {st }}$-day-old pea seedlings grown on the water solution of compound №VI -6- $\{4-\mathrm{Oxo}-3 H, 4 H, 7 H$-pyrazolo[3,4-d] [1,2,3] triazin-7-yl $\}-1,2-$ dihydroisoquinolin-1-one used at concentration $10^{-9} \mathrm{M} / 1$ of distilled water (Figure 10).

It was found also the increase of synthesis of chlorophyll b in 
the cells of leaves of $21^{\text {st }}$-day-old pea seedlings grown on the water solution of compound № IV-7-(1,3-Benzothiazol-2-yl)$3 H, 4 H, 7 H$-pyrazolo[3,4-d] [1,2,3] triazin-4-one used at concentration $10^{-9} \mathrm{M} / 1$ of distilled water; the content of chlorophyll $\mathrm{b}$ was increased at the $16 \%$ and $9 \%$ as compared with control and IAA, respectively (Figure 10).

The similar increase of synthesis of chlorophyll b was observed in the cells of leaves of $21^{\text {st }}$-day-old pea seedlings grown on the water solution of compound № $\mathrm{V}$-2-\{4-Oxo-7-phenyl-3H,4H,7Hpyrazolo[3,4-d] [1,2,3]triazin-3-yl $\}$ acetic acid; the content of chlorophyll b was increased at the $9 \%$ and $3 \%$ as compared with control and IAA, respectively (Figure 10).

At the same time the decrease of content of chlorophyll $\mathrm{b}$ at the $22 \%, 27 \%, 33 \%$ as compared with control, IAA and NAA, respectively, was shown in the cells of leaves of $21^{\text {st }}$-day-old pea seedlings grown on the water solution of compound №VI 6- $\{4-\mathrm{Oxo}-3 H, 4 H, 7 H$-pyrazolo[3,4-d] [1,2,3] triazin-7-yl $\}$-1,2-dihydroisoquinolin-1-one used at concentration $10^{-9} \mathrm{M} / 1$ of distilled water (Figure 10).

The increase of content of chlorophylls $a+b$ in the cells of leaves of $21^{\text {st }}$-day-old pea seedlings grown on the water solution of compound № IV - 7-(1,3-Benzothiazol-2-yl)-3H,4H,7Hpyrazolo[3,4- $d][1,2,3]$ triazin-4-one. The content chlorophylls $\mathrm{a}+\mathrm{b}$ was increased in the cells of leaves of $21^{\text {st }}$-day-old pea seedlings grown on the water solution of compound № IV - at the $26 \%$, $20 \%$ and $9 \%$ as compared with control, IAA and NAA, respectively (Figure 10).

It was observed also the increase of content of chlorophylls $\mathrm{a}+\mathrm{b}$ in the cells of leaves of $21^{\text {st }}$-day-old pea seedlings grown on the water solution of compound № V-2-\{4-Oxo-7-phenyl$3 H, 4 H, 7 H$-pyrazolo[3,4-d] [1,2,3] triazin-3-yl $\}$ acetic acid used at concentration $10^{-9} \mathrm{M} / 1$ of distilled water at the $8 \%$ and $3 \%$ as compared with control, and IAA, respectively (Figure 10).

The increase of chlorophylls a/b ratio at the $11 \%, 13 \%$ and $12 \%$ as compared with control, IAA and NAA, respectively, was also observed in the cells of leaves of $21^{\text {st }}$-day-old pea seedlings grown on the water solution of compound № IV - 7-(1,3-Benzothiazol2-yl)-3H,4H,7H-pyrazolo[3,4-d][1,2,3]triazin-4-one used at concentration $10^{-9} \mathrm{M} / 1$ of distilled water (Figure 10).

It was also found that chlorophylls a/b ratio in the cells of leaves of $21^{\text {st }}$-day-old pea seedlings grown on the water solution of compound № V-2-\{4-Oxo-7-phenyl-3H,4H,7H-pyrazolo[3,4-d] $[1,2,3]$ triazin-3-yl $\}$ acetic acid used at concentration $10^{-9} \mathrm{M} / 1$ of distilled water was higher at the $8 \%$ and $3 \%$ as compared to control and IAA, respectively (Figure 10).

Despite of decrease of content of chlorophylls $\mathrm{a}+\mathrm{b}$ in the cells of leaves of $21^{\text {st }}$-day-old pea seedlings grown on the water solution of compound № VI - 6- $\{4-\mathrm{Oxo}-3 H, 4 H, 7 H$-pyrazolo[3,4- $d]$ $[1,2,3]$ triazin-7-yl $\}-1,2$-dihydroisoquinolin-1-one used at concentration $10^{-9} \mathrm{M} / 1$ of distilled water, the chlorophylls a/b ratio was increased in the cells of these plants at the $5 \%, 7 \%$ and $6 \%$ as compared with control, IAA and NAA, respectively (Figure 10).

Study of quantitative content of carotenoids showed that the content of carotenoids in the cells of leaves of $21^{\text {st }}$-day-old pea seedlings grown on the water solution of compound № IV - 7-(1,3-Benzothiazol-2-yl)-3H,4H,7H-pyrazolo[3,4-d][1,2,3] triazin-4-one used at concentration $10^{-9} \mathrm{M} / 1$ of distilled water was increased at the $33 \%, 26 \%$ and $10 \%$ as compared with control, IAA and NAA, respectively (Figure 10).

It was also demonstrated that the content of carotenoids in the cells of leaves of $21^{\text {st }}$-day-old pea seedlings grown on the water solution of compound № $\mathrm{V}-2-\{4-\mathrm{OxO}-7-$ phenyl-3H,4H,7Hpyrazolo[3,4-d] [1,2,3]triazin-3-yl $\}$ acetic acid used at concentration $10^{-9} \mathrm{M} / 1$ of distilled water was increased at the $8 \%$ as compared with control (Figure 10).

In contrast, the decrease of content of carotenoids at the 5\%,9\% and $21 \%$ as compared with control, IAA and NAA, respectively, was observed in the cells of leaves of $21^{\text {st }}$-day-old pea seedlings grown on the water solution of compound №VI - 6-\{4-Oxo$3 H, 4 H, 7 H$-pyrazolo[3,4-d] [1,2,3] triazin-7-yl\}-1,2-dihydroisoquinolin-1-one used at concentration $10^{-9} \mathrm{M} / 1$ of distilled water (Figure 10).

Figure 10. Impact of synthetic heterocyclic compounds derivatives of pyrazole and phytohormones auxins IAA and NAA on the content of chlorophyll a, chlorophyll b, and carotenoids in the leaves of the $21^{\text {st }}$-day-old seedlings of pea (Pisum sativum L.) of cultivar L303/04 semi-dwarf bewhiskered. Control (distilled water), IAA - Compound $1 H$-Indol-3-ylacetic acid, NAA - Compound 1-Naphthylacetic acid, Compound № IV - 7-(1,3-Benzothiazol-2-yl)-3H,4H,7 H-pyrazolo[3,4- $d]$ [1,2,3] triazin-4-one, Compound № V -2-\{4-Oxo-7-phenyl-3H,4H,7 $H$-pyrazolo[3,4-d] [1,2,3] triazin-3-yl\}acetic acid, Compound № VI - 6-\{4-Oxo-3H,4H,7 H-pyrazolo[3,4-d] [1,2,3] triazin-7-yl\}-1,2-dihydroisoquinolin-1-one.

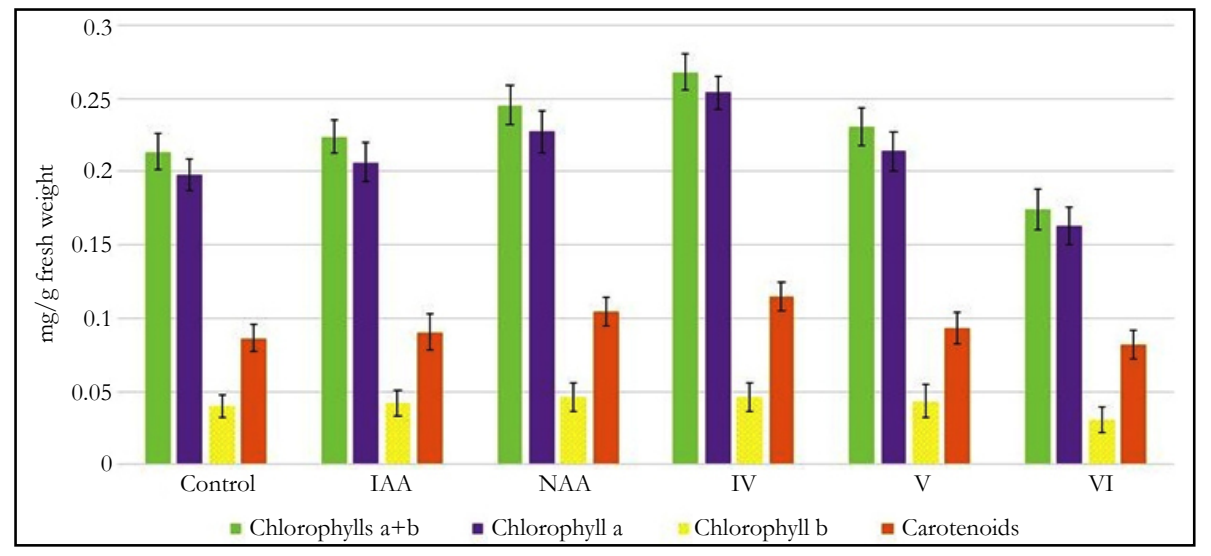


Obviously the decrease of total content of chlorophyll a, chlorophyll b, and carotenoids in the cells of leaves of $21^{\text {st }}$-day-old pea seedlings grown on the water solution of compound VI 6- $\{4$-Oxo-3H,4H,7H-pyrazolo[3,4-d] [1,2,3]triazin-7-yl $\}-1,2-$ dihydroisoquinolin-1-one may be explained its specific auxin-like stimulating effect on acceleration of growth and development of vegetative organs and root system of $21^{\text {st }}$-day-old pea seedlings at while reducing the total content of pigments per unit area of plant biomass.

The minor changes in the carotenoid/chlorophyll ratio in the cells

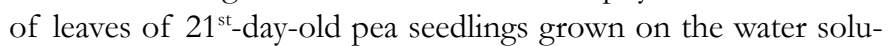
tion of heterocyclic compounds № IV and № VI used at concentration $10^{-9} \mathrm{M} / 1$ of distilled water; the carotenoid/chlorophyll ratio was increased at the $5 \%$ and $14 \%$, respectively, as compared to control.

It was observed also the minor changes in the carotenoid/chlorophyll ratio in the cells of leaves of $21^{\text {st }}$-day-old pea seedlings grown on the water solution of heterocyclic compound № $\mathrm{V}$ used at concentration $10^{-9} \mathrm{M} / 1$ of distilled water; the carotenoid/ chlorophyll ratio was increased at the $6 \%$ as compared to NAA.

The similar changes in the balance of endogenous photosynthetic pigments were observed in the leaves of $21^{\text {st }}$-day-old pea seedlings grown on the water solution of auxin NAA used at concentration $10^{-9} \mathrm{M} / 1$ of distilled water; the carotenoid/chlorophyll ratio was increased at the $5 \%$ as compared to control.

The conducted researches confirmed the impact of some from tested synthetic heterocyclic compounds derivatives of pyrazole and phytohormone auxin NAA on change of the balance of endogenous photosynthetic pigments in the leaves of $21^{\text {st }}$-dayold seedlings of pea (Pisum sativum L.) of cultivar L303/04 semidwarf bewhiskered.

Study of cytokinin-like activity of synthetic heterocyclic compounds derivatives of pyrazole on the isolated cotyledons of muscat pumpkin (Cucurbita moschata Duch. et Poir.) of cultivar Gilea

Study of cytokinin-like growth regulating activity of synthetic heterocyclic compounds derivatives of pyrazole conducted on the isolated cotyledons from seeds of muscat pumpkin (Cucurbita moschata Duch. et Poir.) of cultivar Gilea showed that all tested compounds revealed high cytokinin-like activity. The obtained indexes of growth of biomass of the isolated cotyledons of pumpkin incubated during 16 days on the water solution of some from tested synthetic heterocyclic compounds used at concentration $10^{-9} \mathrm{M} / 1$ of distilled water were similar or higher than the indexes of growth of biomass of isolated cotyledons of pumpkin incubated during 16 days on the water solution of phytohormone cytokinin Kinetin used at the same concentration $10^{-9} \mathrm{M} / 1$ of distilled water as compared with control (Figure 11).

Among the synthetic heterocyclic compounds the highest growth regulating activity revealed the compound № $\mathrm{V}-2-\{4-\mathrm{Oxo}-$ 7-phenyl-3H,4H,7H-pyrazolo[3,4-d] [1,2,3]triazin-3-yl $\}$ acetic acid; the indexes of growth of biomass of the isolated cotyledons of pumpkin grown on the water solution of compound № V used at concentration $10^{-9} \mathrm{M} / 1$ of distilled water were higher at the $27 \%$ and $10 \%$ than the indexes of growth of biomass of the isolated cotyledons of pumpkin grown either on the distilled water (control) or on the water solution of cytokinin Kinetin used at the same concentration $10^{-9} \mathrm{M} / \mathrm{l}$ of distilled water, respectively (Figure 11).

The high growth regulating activity demonstrated also compound № IV-7-(1,3-Benzothiazol-2-yl)-3H,4H,7H-pyrazolo[3,4-d] [1,2,3] triazin-4-one; the indexes of growth of biomass of the isolated cotyledons of pumpkin grown on the water solution of compound № IV used at concentration $10^{-9} \mathrm{M} / 1$ of distilled waterwere higher at the $23 \%$ and $6 \%$ than the indexes of growth of biomass of the isolated cotyledons of pumpkin grown either on the distilled water (control) or on the water solution of cytokinin Kinetin used at the same concentration $10^{-9} \mathrm{M} / 1$ of distilled water, respectively (Figure 11).

The lower growth regulating activity demonstrated compound №VI-6- $\{4$-Oxo-3H,4H,7H-pyrazolo[3,4-d][1,2,3]triazin7-yl -1,2-dihydroisoquinolin-1-one; the indexes of growth of biomass of the isolated cotyledons of pumpkin grown on the water solution of compound № VI used at concentration $10^{-9} \mathrm{M} / 1$ of distilled water were higher at the $12 \%$ than the indexes of growth of biomass of the isolated cotyledons of pumpkin grown on the distilled water (control) (Figure 11).

Thus, the obtained results confirmed high cytokinin-like growth regulating activity of synthetic heterocyclic compounds derivatives of pyrimidine, which was similar or higher of activity of phytohormone Kinetin. Obviously that growth regulating activity of synthetic heterocyclic compounds may be explained by their specific cytokinin-like inducing effect on cell division and cell elongation, as well as activation of biosynthetic processes in the cells of isolated cotyledons of muscat pumpkin (Cucurbita moschata Duch. et Poir.) of cultivar Gilea resulting in an increasing of their growth and biomass.

Stimulating effect of synthetic heterocyclic compounds phosphorylated derivatives of oxazole and pyrimidine on vegetative growth of maize (Zea mays L.) hybrid Palmyra FAO 190

In the laboratory conditions we studied also growth regulating activity of synthetic heterocyclic compounds phosphorylated derivatives of oxazole and pyrimidine used at concentration $10^{-9} \mathrm{M} / 1$ of distilled water according to their impact on germination of seeds and vegetative growth of seedlings of maize (Zea mays L.) hybrid Palmyra FAO 190 (Figure 12).

The growth regulating activity of synthetic heterocyclic compounds was compared with the activity of phytohormones auxins IAA and NAA used at the same concentration $10^{-9} \mathrm{M} / 1$ of distilled water.

The obtained results showed that all tested heterocyclic compounds revealed high stimulating effect on growth of the $14^{\text {th }}$ day-old seedlings of maize (Zea mays L.) hybrid Palmyra FAO 190 (Figure 12).

It was found also that all synthetic heterocyclic compounds considerably stimulated growth and development of roots on the $14^{\text {th }}$-day-old maize seedlings, and their stimulating effect was simi- 
Figure 11. Impact of synthetic heterocyclic compounds derivatives of pyrazole and phytohormone cytokinin Kinetin on growth of biomass of isolated cotyledons from seeds of muscat pumpkin (Cucurbita moschata Duch. et Poir.) of cultivar Gilea during the 16 days. Control (distilled water), Compound №IV - 7-(1,3-Benzothiazol-2-yl)-3H,4H,7 H-pyrazolo[3,4d] [1,2,3]triazin-4-one, Compound №V -2-\{4-Oxo-7-phenyl-3H,4H,7 H-pyrazolo[3,4-d] [1,2,3]triazin-3-yl\}acetic acid, Compound №VI - 6-\{4-Oxo-3H,4H,7H-pyrazolo[3,4-d] [1,2,3]triazin-7-yl\}-1,2-dihydroisoquinolin-1-one.

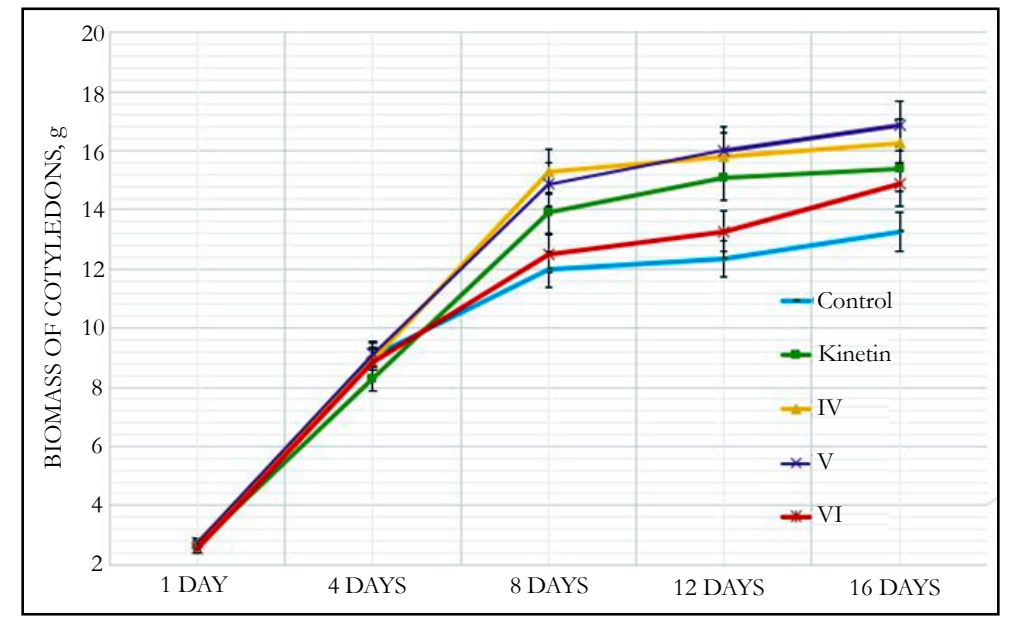

Figure 12. Impact of synthetic heterocyclic compounds phosphorylated derivatives of oxazole and pyrimidine, as well as phytohormones auxins IAA and NAA on vegetative growth of the $14^{\text {th }}$-day-old seedlings of maize (Zea mays L.) hybrid Palmyra FAO 190. C - Control (distilled water), IAA - Compound $1 H$-Indol-3-ylacetic acid, NAA - Compound 1-Naphthylacetic acid, Compound VII- Diethyl ester \{5-[(2-Hydroxyethyl)-methyl-amino]-2-phenyl-1,3-oxazol-4-yl\}phosphonic acid, Compound VIII - Diethyl ester [5-(3-Hydroxypiperidin-1-yl)-2-phenyl-1,3-oxazol-4-yl]phosphonic acid, Compound IX 4-Benzylamino-5-p-tolyl-5H-pyrrolo-[3,2- $d$ ] pyrimidin-7-yl)phosphonic acid diethyl ester.

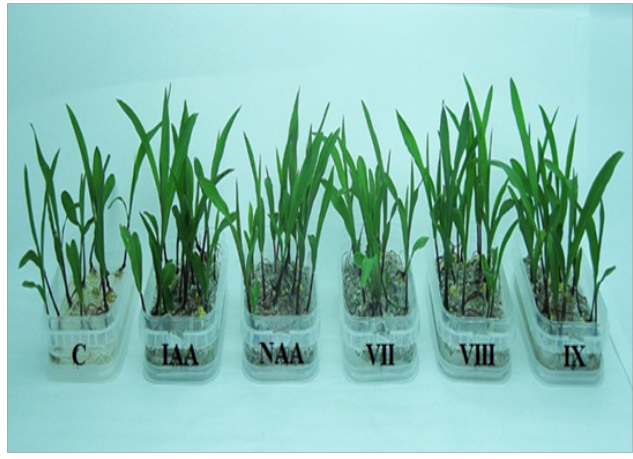

Figure 13. Impact of synthetic heterocyclic compounds phosphorylated derivatives of oxazole and pyrimidine, as well as phytohormones auxins IAA and NAA on growth of roots on the $14^{\text {th }}$-day-old seedlings of maize (Zea mays L.) hybrid Palmyra FAO 190. C - Control (distilled water), IAA - Compound $1 H$-Indol-3-ylacetic acid, NAA - Compound 1-Naphthylacetic acid, Compound VII - Diethyl ester \{5-[(2-Hydroxyethyl)-methyl-amino]-2-phenyl-1,3-oxazol-4-yl\} phosphonic acid, Compound VIII - Diethyl ester [5-(3-Hydroxypiperidin-1-yl)-2-phenyl-1,3-oxazol-4-yl]phosphonic acid, Compound IX 4-Benzylamino-5-p-tolyl-5H-pyrrolo-[3,2- $d$ pyrimidin-7-yl)phosphonic acid diethyl ester.

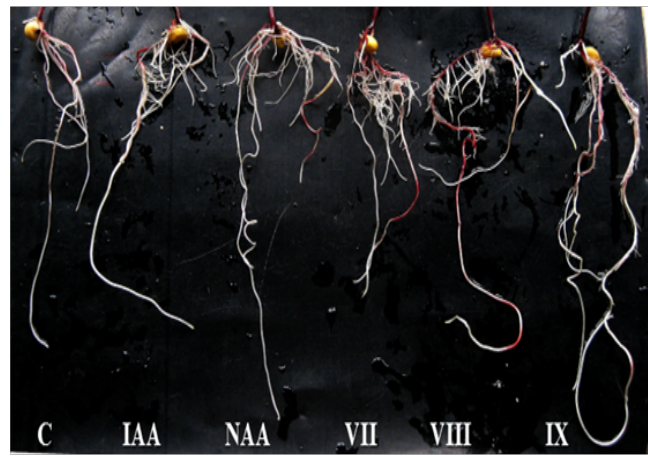


lar or higher than the effect of phytohormones auxins IAA and NAA (Figure 13).

The comparative analysis of biometric indexes of $14^{\text {th }}$-day-old seedlings of maize (i.e. number of germinated seeds (\%), length of seedlings $(\mathrm{cm})$, total number of roots (pcs), total length of roots $(\mathrm{mm})$ ) showed that the biometric indexes of $14^{\text {th }}$-dayold maize seedlings grown on the water solution of chemical heterocyclic compounds phosphorylated derivatives of oxazole and pyrimidine used at concentration $10^{-9} \mathrm{M} / 1$ of distilled water were as generally similar or higher than the biometric indexes of $14^{\text {th }}$-day-old maize seedlings grown on the water solution of phytohormones auxins IAA and NAA used at the same concentration $10^{-9} \mathrm{M} / 1$ of distilled water as compared to lower biometric indexes of $14^{\text {th }}$-day-old maize seedlings grown on the distilled water (control) (Figure 14).

Particularly it was found that the highest growth regulating activity revealed the compound № VII - Diethyl ester \{5-[(2-Hydroxyethyl)-methyl-amino]-2-phenyl-1,3-oxazol-4-yl $\}$ phosphonic acid; the biometric indexes of $14^{\text {th }}$-day-old maize seedlings grown on the water solution of this compound used at concentration $10^{-9} \mathrm{M} / 1$ of distilled water were as generally higher than the biometric indexes of $14^{\text {th }}$-day-old maize seedlings grown either on the distilled water (control) or on the water solution of auxins IAA and NAA used at the same concentration $10^{-9} \mathrm{M} / 1$ of distilled water as follows: according with total length of roots - at the $37 \%, 34 \%$ and $13 \%$ as compared with control, IAA and NAA, respectively; according with total number of roots - at the $47 \%$, $39 \%$ and $7 \%$ as compared with control, IAA and NAA, respectively (Figure 14).

The high growth regulating activity revealed the compound № VIII - Diethyl ester [5-(3-Hydroxypiperidin-1-yl)-2-phenyl-1,3oxazol-4-yl]phosphonic acid; the biometric indexes of $14^{\text {th }}$-dayold maize seedlings grown on the water solution of this compound used at concentration $10^{-9} \mathrm{M} / 1$ of distilled water were as generally higher than the biometric indexes of $14^{\text {th }}$-day-old maize seedlings grown on the distilled water (control) as follows: ac- cording with length of seedlings - at the $23 \%$ as compared with control; according with total length of roots - at the $18 \%$ and $16 \%$ as compared with control and IAA, respectively; according with total number of roots - at the $52 \%, 44 \%$ and $11 \%$ as compared with control, IAA and NAA, respectively (Figure 14).

The high growth regulating activity revealed also the compound № IX - 4-Benzylamino-5-p-tolyl-5H-pyrrolo-[3,2-d]pyrimidin7 -yl)phosphonic acid diethyl ester; the biometric indexes of $14^{\text {th }}$ day-old maize seedlings grown on the water solution of this compound used at concentration $10^{-9} \mathrm{M} / 1$ of distilled water were as generally higher than the biometric indexes of $14^{\text {th }}$-day-old maize seedlings grown on the distilled water (control) as follows: according with total length of roots - at the $27 \%, 25 \%$ and $5 \%$ as compared with control, IAA and NAA, respectively; according with total number of roots - at the $87 \%, 77 \%$ and $36 \%$ as compared with control, IAA and NAA, respectively (Figure 14).

Based on the obtained results it is possible to assume that high growth stimulating activity of synthetic heterocyclic compounds phosphorylated derivatives of oxazole and pyrimidine, which is similar to activity of phytohormones auxins, may be explained by their inducing effect on the plant cell division, cell elongation, cell proliferation, cell differentiation, and the increase of cell metabolism, resulting in an improving of growth and development of maize (Zea mays L.) hybrid Palmyra FAO 190.

Impact of synthetic heterocyclic compounds phosphorylated derivatives of oxazole and pyrimidine on the total content of pigments in the leaves of maize (Zea mays L.) hybrid Palmyra FAO 190

In our work we also studied impact of synthetic heterocyclic compounds phosphorylated derivatives of oxazole and pyrimidine used at concentration $10^{-9} \mathrm{M} / 1$ of distilled water on the total content of chlorophylls (including chlorophyll a and chlorophyll b), as well as carotenoids in the leaves of $14^{\text {th }}$-day-old seedlings of maize (Zea mays L.) hybrid Palmyra FAO 190. The activity of synthetic heterocyclic compounds was compared with the activity

Figure 14. Impact of synthetic heterocyclic compounds phosphorylated derivatives of oxazole and pyrimidine and phytohormones auxins IAA and NAA on biometric indexes of the $14^{\text {th }}$-day-old seedlings of maize (Zea mays L.) hybrid Palmyra FAO 190. Control (distilled water), IAA - Compound $1 H$-Indol-3-ylacetic acid, NAA - Compound 1-Naphthylacetic acid, Compound VII- Diethyl ester \{5-[(2-Hydroxyethyl)-methyl-amino]-2-phenyl-1,3-oxazol-4-yl\}phosphonic acid, CompoundVIII - Diethyl ester [5-(3-Hydroxypiperidin-1-yl)-2-phenyl-1,3-oxazol-4-yl]phosphonic acid, Compound IX - 4-Benzylamino5-p-tolyl-5H-pyrrolo-[3,2-d]pyrimidin-7-yl)phosphonic acid diethyl ester. A - Number of germinated seeds (\%), B - length of seedlings $(\mathrm{cm}), \mathrm{C}$ - total length of roots $(\mathrm{mm}), \mathrm{D}$ - total number of roots (pcs).

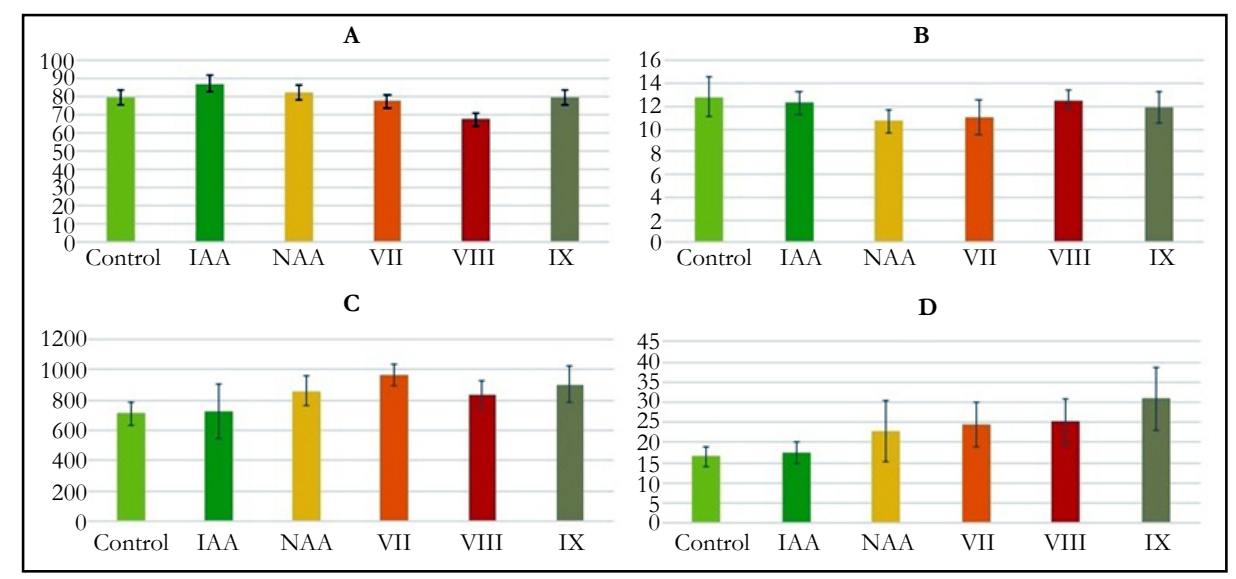


of phytohormones auxins IAA and NAA that were used at the same concentration $10^{-9} \mathrm{M} / 1$ of distilled water.

The obtained results showed that some from tested heterocyclic compounds revealed stimulating effect on synthesis of pigments in the leaves of $14^{\text {th }}$-day-old maize seedlings grown on the water solution of the synthetic heterocyclic compounds (Figure 15).

The increase of synthesis of chlorophyll a was observed in the cells of leaves of $14^{\text {th }}$-day-old maize seedlings grown on the water solution of compound № IX - 4-Benzylamino-5-p-tolyl-5Hpyrrolo-[3,2-d]pyrimidin-7-yl)phosphonic acid diethyl ester used at concentration $10^{-9} \mathrm{M} / 1$ of distilled water; the content of chlorophylla was increased at the $8 \%, 8 \%$ and $10 \%$ as compared with control, IAA and NAA, respectively (Figure 15).

In contrast, the decrease of synthesis of chlorophyll a was observed in the cells of leaves of $14^{\text {th }}$-day-old maize seedlings grown on the water solution of compound №VII- Diethyl ester \{5-[(2-Hydroxyethyl)-methyl-amino]-2-phenyl-1,3-oxazol-4-yl $\}$ phosphonic acid used at concentration $10^{-9} \mathrm{M} / 1$ of distilled water; the content of chlorophyll a was decreased at the $3 \%$ as compared with control (Figure 15).

Similar decrease of synthesis of chlorophyll a was observed in the cells of leaves of $14^{\text {th }}$-day-old maize seedlings grown on the water solution of compound № VIII - Diethyl ester [5-(3-Hydroxypiperidin-1-yl)-2-phenyl-1,3-oxazol-4-yl]phosphonic acid; the content of chlorophyll a was decreased at the $5 \%$ as compared with control (Figure 15).

At the same time the increase of synthesis of chlorophyll b was found in the cells of leaves of $14^{\text {th }}$-day-old maize seedlings grown on the water solution of compound № VII - Diethyl ester $\{5$-[(2-Hydroxyethyl)-methyl-amino]-2-phenyl-1,3-oxazol-4-yl $\}$ phosphonic acid used at concentration $10^{-9} \mathrm{M} / 1$ of distilled water; the content of chlorophyll b was increased at the $74 \%$ and $39 \%$ as compared with control and IAA, respectively (Figure 15).
The increase of synthesis of chlorophyll b was also observed in the cells of leaves of $14^{\text {th }}$-day-old maize seedlings grown on the water solution of compound № VIII - Diethyl ester [5-(3-Hydroxypiperidin-1-yl)-2-phenyl-1,3-oxazol-4-yl]phosphonic acid; the content of chlorophyll $\mathrm{b}$ was increased at the $45 \%$ and $15 \%$ as compared with control and IAA, respectively (Figure 15).

The increase of content of chlorophyll $\mathrm{b}$ at the $38 \%$ and $10 \%$ as compared with control and IAA, respectively, was shown also in the cells of leaves of $14^{\text {th }}$-day-old pea seedlings grown on the water solution of compound № IX - 4-Benzylamino-5-p-tolyl-5Hpyrrolo-[3,2-d]pyrimidin-7-yl)phosphonic acid diethyl ester used at concentration $10^{-9} \mathrm{M} / 1$ of distilled water (Figure 15).

It was observed the increase of content of chlorophylls $\mathrm{a}+\mathrm{b}$ at the $11 \%, 9 \%$ and $5 \%$ as compared with control, IAA and NAA, respectively, in the cells of leaves of $14^{\text {th }}$-day-old maize seedlings grown on the water solution of compound № IX - 4-Benzylamino-5-p-tolyl-5H-pyrrolo-[3,2-d]pyrimidin-7-yl)phosphonic acid diethyl ester (Figure 15).

The increase of content of chlorophylls $a+b$ at the $4 \%$ and $2 \%$ as compared with control and IAA, respectively, was found in the cells of leaves of $14^{\text {th }}$-day-old maize seedlings grown on the water solution of compound № VII - Diethyl ester \{5-[(2-Hydroxyethyl)methyl-amino]-2-phenyl-1,3-oxazol-4-yl $\}$ phosphonic acid used at concentration $10^{-9} \mathrm{M} / 1$ of distilled water (Figure 15).

At the same time the decrease of chlorophylls $a / b$ ratio at the $44 \%$ and $30 \%$ as compared with control and IAA, respectively, was observed in the cells of leaves of $14^{\text {th }}$-day-old maize seedlings grown on the water solution of compound № VII - Diethyl ester $\{5$-[(2-Hydroxyethyl)-methyl-amino]-2-phenyl-1,3-oxazol-4-yl $\}$ phosphonic acid used at concentration $10^{-9} \mathrm{M} / 1$ of distilled water (Figure 15).

The decrease of chlorophylls a/b ratio at the $34 \%$ and $17 \%$ as compared with control and IAA, respectively, was observed also in the cells of leaves of $14^{\text {th }}$-day-old maize seedlings grown on

Figure 15. Impact of synthetic heterocyclic compounds phosphorylated derivatives of oxazole and pyrimidine and phytohormones auxins IAA and NAA on the content of chlorophyll a, chlorophyll $b$, and carotenoids in the leaves of the $14^{\text {th }}$-day-old seedlings of maize (Zea mays L.) hybrid Palmyra FAO 190. Control (distilled water), IAA - Compound $1 H$-Indol-3-ylacetic acid, NAA - Compound 1-Naphthylacetic acid, Compound VII- Diethyl ester \{5-[(2-Hydroxyethyl)methyl-amino]-2-phenyl-1,3-oxazol-4-yl\}phosphonic acid, Compound VIII - Diethyl ester [5-(3-Hydroxypiperidin-1-yl)2-phenyl-1,3-oxazol-4-yl]phosphonic acid, Compound IX - 4-Benzylamino-5-p-tolyl-5H-pyrrolo-[3,2-d]pyrimidin-7-yl) phosphonic acid diethyl ester.

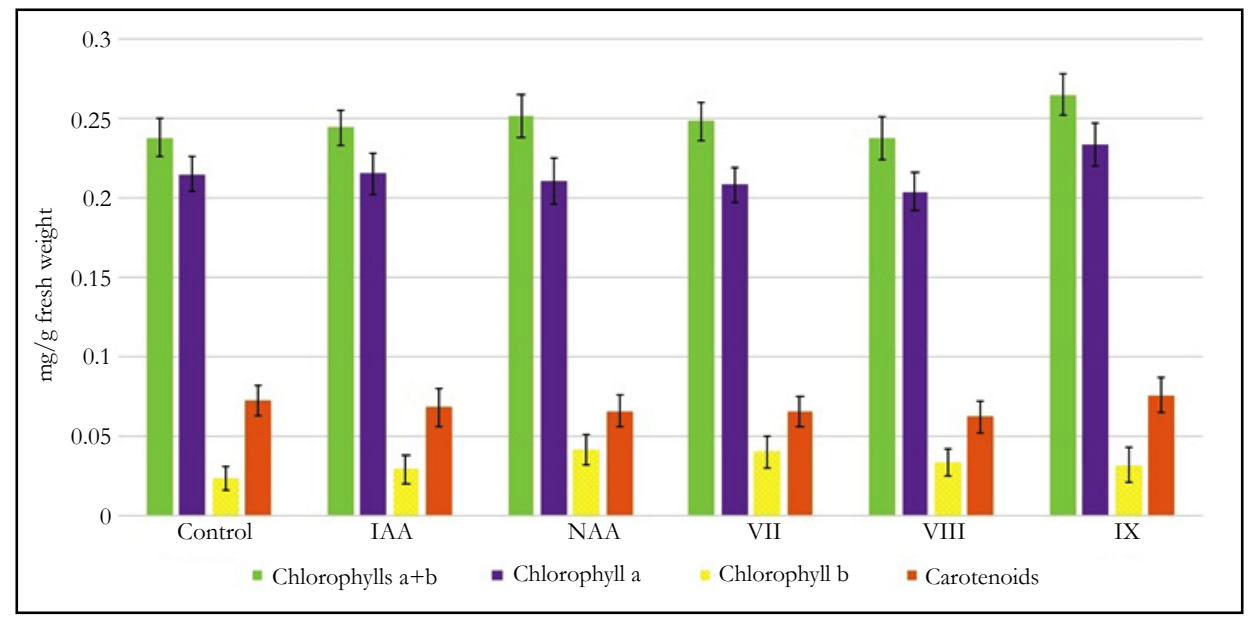


the water solution of compound № VIII - Diethyl ester [5-(3-Hydroxypiperidin-1-yl)-2-phenyl-1,3-oxazol-4-yl]phosphonic acid (Figure 15).

Similar changes were observed in the cells of leaves of $14^{\text {th }}$-dayold maize seedlings grown on the water solution of compound № IX-4-Benzylamino-5-p-tolyl-5H-pyrrolo-[3,2-d]pyrimidin-7-yl) phosphonic acid diethyl ester; the chlorophylls $\mathrm{a} / \mathrm{b}$ ratio was decreased at the $21 \%$ as compared with control (Figure 15).

Thus the obtained data confirmed positive effects of some synthetic heterocyclic compounds phosphorylated derivatives of oxazole and pyrimidine on the synthesis of pigments of plant photosystem - chlorophylls a and b that play a key role in the photosynthetic processes in the leaves of $14^{\text {th }}$-day-old maize seedlings. At the same time, the results showed the effect of these compounds on the decline of chlorophyll a/b ratio. This fact indicates the selectivity of action of these compounds towards the intensification of biosynthesis of chlorophyll b, which is known to take an important part in plant adaptation to environmental stress factors [162].

Study of quantitative content of carotenoids showed that the content of carotenoids in the cells of leaves of $14^{\text {th }}$-day-old maize seedlings grown on the water solution of compounds № VII Diethyl ester \{5-[(2-Hydroxyethyl)-methyl-amino]-2-phenyl-1,3oxazol-4-yl $\}$ phosphonic acid and № VIII - Diethyl ester [5-(3-Hydroxypiperidin-1-yl)-2-phenyl-1,3-oxazol-4-yl]phosphonic acid used at concentration $10^{-9} \mathrm{M} / 1$ of distilled water was decreased at the $10 \%$ and $14 \%$ as compared with control, respectively, while there was no any significant changes in the content of carotenoids in the cells of leaves of $21^{\text {st }}$-day-old maize seedlings grown on the water solution of compound № IX - 4-Benzylamino-5-p-tolyl-5H-pyrrolo-[3,2-d]pyrimidin-7-yl)phosphonic acid diethyl ester used at concentration $10^{-9} \mathrm{M} / 1$ of distilled water (Figure 15).

The changes in the carotenoid/chlorophyll ratio were observed in the leaves of $14^{\text {th }}$-day-old maize seedlings grown on the water solution of compounds № VII, № VIII and № IX used at the concentration $10^{-9} \mathrm{M} / 1$ of distilled water; the carotenoid/chloro- phyll ratio was decreased at the $16 \%, 17 \%$ and $7 \%$, respectively, as compared to control.

The similar changes in the balance of endogenous photosynthetic pigments was observed in the leaves of $14^{\text {th }}$-day-old maize seedlings grown on the water solution of auxins IAA and NAA used at concentration $10^{-9} \mathrm{M} / 1$ of distilled water; the carotenoid/chlorophyll ratio was decreased at the $11 \%$ and $19 \%$, respectively, as compared to control.

This fact testifies about the change of the balance of endogenous photosynthetic pigments towards the increase of biosynthesis of chlorophylls and decrease of biosynthesis of carotenoids in the $14^{\text {th }}$-day-old seedlings of maize (Zea mays L.) hybrid Palmyra FAO 190 occurred under impact of tested heterocyclic compounds and phytohormones auxins IAA and NAA.

Study of cytokinin-like activity of synthetic heterocyclic compounds phosphorylated derivatives of oxazole and pyrimidine on the isolated cotyledons of muscat pumpkin (Cucurbita moschata Duch. et Poir.) of cultivar Gilea

The cytokinin-like growth regulating activity of synthetic heterocyclic compounds phosphorylated derivatives of oxazole and pyrimidine was conducted on the isolated cotyledons from seeds of muscat pumpkin (Cucurbita moschata Duch. et Poir.) of cultivar Gilea. It was shown that all tested compounds demonstrated high cytokinin-like activity.

The obtained indexes of growth of biomass of the isolated cotyledons of pumpkin incubated during 16 days on the water solution of synthetic heterocyclic compounds used at concentration $10^{-9} \mathrm{M} / 1$ of distilled water were similar or higher than the indexes of growth of biomass of isolated cotyledons of pumpkin incubated during 16 days on the water solution of phytohormone cytokinin Kinetin used at the same concentration $10^{-9} \mathrm{M} / 1$ of distilled water as compared with control (Figure 16).

The obtained results showed that the highest growth regulating activity revealed the compound № IX - 4-Benzylamino-5-p-tol-

Figure 16. Impact of synthetic heterocyclic compounds phosphorylated derivatives of oxazole and pyrimidine, and phytohormone cytokinin Kinetin on growth of biomass of isolated cotyledons from seeds of muscat pumpkin (Cucurbita

moschata Duch. et Poir.) of cultivar Gilea during the 16 days. Control (distilled water), Compound VII- Diethyl ester

\{5-[(2-Hydroxyethyl)-methyl-amino]-2-phenyl-1,3-oxazol-4-yl\}phosphonic acid, Compound VIII - Diethyl ester [5-(3-Hydroxypiperidin-1-yl)-2-phenyl-1,3-oxazol-4-yl]phosphonic acid, Compound IX - 4-Benzylamino-5-p-tolyl-5H-pyrrolo-[3,2- $d]$ pyrimidin-7-yl) phosphonic acid diethyl ester.

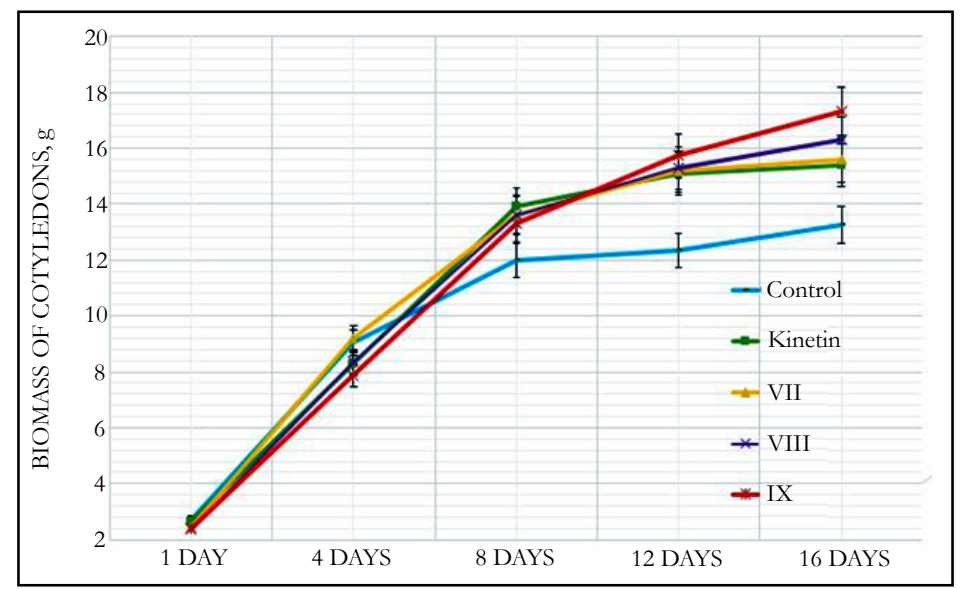


yl-5H-pyrrolo-[3,2-d]pyrimidin-7-yl)phosphonic acid diethyl ester; the indexes of growth of biomass of the isolated cotyledons of pumpkin grown on the water solution of compound № IX used at concentration $10^{-9} \mathrm{M} / 1$ of distilled water were higher at the $30 \%$ and $13 \%$ than the indexes of growth of biomass of the isolated cotyledons of pumpkin grown either on the distilled water (control) or on the water solution of cytokinin Kinetin used at the same concentration $10^{-9} \mathrm{M} / 1$ of distilled water, respectively (Figure 16).

The high growth regulating activity demonstrated compound № VIII - Diethyl ester [5-(3-Hydroxypiperidin-1-yl)-2-phenyl-1,3oxazol-4-yl]phosphonic acid; the indexes of growth of biomass of the isolated cotyledons of pumpkin grown on the water solution of compound № VIII used at concentration $10^{-9} \mathrm{M} / 1$ of distilled water were higher at the $23 \%$ and $6 \%$ than the indexes of growth of biomass of the isolated cotyledons of pumpkin grown either on the distilled water (control) or on the water solution of cytokinin Kinetin used at the same concentration $10^{-9} \mathrm{M} / 1$ of distilled water, respectively (Figure 16).

The lower growth regulating activity demonstrated also compound № VII - Diethyl ester \{5-[(2-Hydroxyethyl)-methylamino]-2-phenyl-1,3-oxazol-4-yl $\}$ phosphonic acid; the indexes of growth of biomass of the isolated cotyledons of pumpkin grown on the water solution of compound № VII used at concentration $10^{-9} \mathrm{M} / 1$ of distilled water were higher at the $18 \%$ than the indexes of growth of biomass of the isolated cotyledons of pumpkin grown on the distilled water (control) (Figure 16).

Thus, the obtained results confirmed high cytokinin-like growth regulating activity of synthetic heterocyclic compounds phosphorylated derivatives of oxazole and pyrimidine, which was similar or higher of activity of phytohormone Kinetin. Obviously that growth regulating activity of synthetic heterocyclic compounds may be explained by their specific cytokinin-like inducing effect on cell division and cell elongation, as well as activation of biosynthetic processes in the cells of isolated cotyledons of muscat pumpkin (Cucurbita moschata Duch. et Poir.) of cultivar Gilea resulting in an increasing of their growth and biomass.

\section{Discussion}

To provide successful development of sustainable agriculture the new intensive technologies based on application of different classes of phytohormones, plant growth regulators of synthetic origin, and biostimulants are used for regulation of genetic program of plant growth and development, improve of quality of crop production and increase of crop resistance to stress-factors of environment [6-65, 86-94].

The elaboration of new effective plant growth regulating substances of natural or chemical origin on the base of different classes of synthetic and natural compounds having plant growth regulating activity similar to activity of phytohormones is a very important task for agricultural biotechnology. To study plant grow regulating activity of new bioactive compounds, the specific bioassays on phytohormone-like activity based on the effect of tested compounds on plant cell division, cell proliferation, cell elongation and cell differentiation in vivo and in vitro conditions are used [156, 157, 166-175]. Study of relationship between chemical structure and biological activity of different classes of synthetic plant growth regulating substances showed that conformational, electronic, and stereochemical features, as well as different substituents in the chemical structure play a major role in determining the growth regulating activity of these substances $[170,171$, 176].

Today the new classes of plant growth regulating substances derivatives of low molecular weight five and six-membered heterocyclic compounds are synthesized in the Institute of Bioorganic Chemistry and Petrochemistry of National Academy of Sciences of Ukraine. Study of the biological activity of these low molecular weight heterocyclic compounds conducted on human and animal cells suggest that this compounds exhibit anticancer, antiviral, antibacterial, antifungal and anti-inflammatory activity [177-181]. Our previous researches devoted to study of plant growth regulating activity of heterocyclic compounds derivatives of pyridine, pyrimidine, pyrazole, and isoflavones showed high auxin-like and cytokinin-like stimulating effect on shoot organogenesis in the culture of isolated tissues of flax and on growth of isolated organs of haricot bean and pumpkin in vitro conditions, as well as on germination of seed and vegetative growth of maize, soybean, wheat, flax and lettuce plants in vivo conditions [151-154].

Based on the literature data and results of our previous researches the our present work was aimed to study of growth regulating activity of synthetic low molecular weight heterocyclic compounds derivatives of pyrimidine, pyrazole, and oxazole according with their stimulating auxin-like effect on seed germination and vegetative growth of economically important agricultural crops such as pea and maize, as well as according with their cytokinin-like effect on growth of biomass of isolated cotyledons of another important agricultural plant - pumpkin.

The obtained results testify that all tested synthetic low molecular weight heterocyclic compounds derivatives of pyrimidine, pyrazole, and oxazole used at very low nanomolar concentration $10^{-9} \mathrm{M} / 1$ of distilled water manifested high auxin-like stimulating effect on the vegetative growth of two cultivars of pea (Pisum sativum L.) - of cultivar L35/11 middle stalwart bewhiskered and cultivar L303/04 semi-dwarf bewhiskered, and maize (Zea mays L.) hybrid Palmyra FAO 190.

The activity of tested synthetic low molecular weight heterocyclic compounds derivatives of pyrimidine, pyrazole, and oxazole used at concentration $10^{-9} \mathrm{M} / 1$ of distilled water was similar or higher than the activity of phytohormones auxins IAA and NAA, and cytokinin Kinetin used at the same concentration $10^{-9} \mathrm{M} / 1$ of distilled water. The obtained biometric indexes of pea and maize seedlings grown on the water solution of heterocyclic compounds used at concentration $10^{-9} \mathrm{M} / 1$ of distilled water were in average similar or higher of the biometric indexes of pea and maize seedlings grown either on the distilled water (control) or on the water solution of auxins IAA and NAA used at the same concentration $10^{-9} \mathrm{M} / \mathrm{l}$ of distilled water.

Among the tested synthetic low molecular weight heterocyclic compounds derivatives of pyrimidine, pyrazole, and oxazole the highest growth regulating activity showed compounds: the compound № II -7-(2-Hydroxyethyl)-9-methanesulfonyl-2,3,4,7tetrahydropyrimido[1,6-a]pyrimidin-6-one hydrochloride, the compound № III - 6-(2-Hydroxyethyl)-8-methanesulfonyl-2,6- 
dihydro-3H-imidazo[1,2-c]pyrimidine-5-one hydrochloride, the compound № V -2-\{4-Oxo-7-phenyl-3H,4H,7H-pyrazolo[3,4-d] $[1,2,3]$ triazin-3-yl $\}$ acetic acid, the compound № VII - Diethyl ester $\{5$-[(2-Hydroxyethyl)-methyl-amino]-2-phenyl-1,3-oxazol4-yl\} phosphonic acid, the compound № VIII - Diethyl ester [5-(3-Hydroxypiperidin-1-yl)-2-phenyl-1,3-oxazol-4-yl]phosphonic acid, and the compound № IX - 4-Benzylamino-5-p-tolyl-5Hpyrrolo-[3,2-d]pyrimidin-7-yl)phosphonic acid diethyl ester.

The lower growth regulating activity revealed heterocyclic compounds: the compound № I - 8-Methanesulfonyl-6-phenyl-2,6dihydro-3H-imidazo[1,2-c]pyrimidin-5-one, the compound № IV - 7-(1,3-Benzothiazol-2-yl)-3H,4H,7H-pyrazolo[3,4-d][1,2,3] triazin-4-one, the compound № VI - 6-\{4-Oxo-3H,4H,7Hpyrazolo[3,4-d] [1,2,3]triazin-7-yl\}-1,2-dihydroisoquinolin-1-one.

It was found also positive stimulating effect of some from tested synthetic low molecular weight heterocyclic compounds derivatives of pyrimidine, pyrazole, and oxazole on synthesis of total chlorophylls and carotenoids in the leaves of pea and maize seedlings. The indexes of content of chlorophyll a, chlorophyll $\mathrm{b}$, chlorophylls $\mathrm{a}+\mathrm{b}$ and chlorophylls $\mathrm{a} / \mathrm{b}$ ratio, as well as carotenoids obtained in the leaves of pea and maize seedlings grown on the water solution of heterocyclic compounds used at concentration $10^{-9} \mathrm{M} / 1$ of distilled water were in average similar or higher of the analogical indexes obtained in the leaves of pea and maize seedlings grown either on the distilled water (control) or on the water solution of auxins IAA and NAA used at the same concentration $10^{-9} \mathrm{M} / 1$ of distilled water.

The highest stimulating effect showed heterocyclic compounds: the compound № I - 8-Methanesulfonyl-6-phenyl-2,6-dihydro-3Himidazo[1,2-c]pyrimidin-5-one, the compound № III-6-(2Hydroxyethyl)-8-methanesulfonyl-2,6-dihydro-3H-imidazo[1,2- $c]$ pyrimidine-5-one hydrochloride, the compound №IV-7-(1,3-Benzothiazol-2-yl)-3H,4H,7H-pyrazolo[3,4-d][1,2,3] triazin-4-one, the compound № V -2-\{4-Oxo-7-phenyl-3H,4H,7H-pyrazolo[3,4-d] $[1,2,3]$ triazin-3-yl $\}$ acetic acid, the compound № IX -4-Benzylamino-5-p-tolyl-5H-pyrrolo-[3,2-d]pyrimidin-7-yl)phosphonic acid diethyl ester.

The lower stimulating effect showed heterocyclic compounds: the compound № II -7-(2-Hydroxyethyl)-9-methanesulfonyl-2,3,4,7tetrahydropyrimido[1,6-a]pyrimidin-6-one hydrochloride, and the compound № VII - Diethyl ester \{5-[(2-Hydroxyethyl)-methylamino]-2-phenyl-1,3-oxazol-4-yl $\}$ phosphonic acid.

The specific bioassay on cytokinin-like activity showed that all tested synthetic low molecular weight heterocyclic compounds derivatives of pyrimidine, pyrazole, and oxazole manifested also expressive cytokinin-like stimulating effect on the growth of biomass of isolated cotyledons of muscat pumpkin (Cucurbita moschata Duch. et Poir.) of cultivar Gilea. The obtained indexes of biomass growth of isolated cotyledons of pumpkin grown on the water solution of heterocyclic compounds used at concentration $10^{-9} \mathrm{M} / 1$ of distilled water were similar or higher of the indexes of biomass growth of isolated cotyledons of pumpkin grown either on the distilled water (control) or on the water solution of phytohormone cytokinin Kinetin used at the same concentration $10^{-9} \mathrm{M} / 1$ of distilled water.

The highest cytokinin-like activity showed heterocyclic com- pounds: the compound № I - 8-Methanesulfonyl-6-phenyl-2,6dihydro-3H-imidazo[1,2-c]pyrimidin-5-one, the compound № III-6-(2-Hydroxyethyl)-8-methanesulfonyl-2,6-dihydro-3Himidazo[1,2-c]pyrimidine-5-one hydrochloride, the compound №IV-7-(1,3-Benzothiazol-2-yl)-3H,4H,7H-pyrazolo[3,4-d] [1,2,3] triazin-4-one, the compound $N o \mathrm{~V}-2-\{4-\mathrm{Oxo}-7$-phenyl-3H,4H,7Hpyrazolo[3,4-d][1,2,3] triazin-3-yl $\}$ acetic acid, the compound № VIII - Diethyl ester [5-(3-Hydroxypiperidin-1-yl)-2-phenyl-1,3oxazol-4-yl]phosphonic acid, the compound № IX - 4-Benzylamino-5-p-tolyl-5H-pyrrolo-[3,2-d]pyrimidin-7-yl)phosphonic acid diethyl ester.

The lower cytokinin-like activity showed heterocyclic compounds: the compound № II -7-(2-Hydroxyethyl)-9-methanesulfonyl2,3,4,7-tetrahydropyrimido[1,6-a]pyrimidin-6-one hydrochloride, the compound № VI - 6- $\{4-\mathrm{OxO}-3 H, 4 H, 7 H$-pyrazolo[3,4-d] $[1,2,3]$ triazin-7-yl $\}-1,2$-dihydroisoquinolin-1-one, and the compound № VII- Diethyl ester $\{5$-[(2-Hydroxyethyl)-methyl-amino]2-phenyl-1,3-oxazol-4-yl $\}$ phosphonic acid.

Taking into account of obtained results it is possible to assume that the high auxin-like and cytokinin-like growth regulating activity of synthetic heterocyclic compounds may be explained by similarity of some fragments of their chemical structure to natural phytohormones auxins and cytokinins or their natural precursors, or their synthetic structural analogues, as well as their specific auxin-like and cytokinin-like inducing effect on cell division, cell elongation, cell differentiation, cell metabolism, and photosynthetic processes, resulting in accelerating of both whole plant organism growth and growth of isolated plant organs $[8$, 18-32, 182-184].

\section{Conclusion}

Study of plant growth regulating activity of synthetic low molecular weight heterocyclic compounds derivatives of pyrimidine, pyrazole, and oxazole used at concentration $10^{-9} \mathrm{M} / 1$ of distilled water showed stimulating auxin-like activity of all tested compounds on vegetative growth of two cultivars of pea (Pisum sativum L.) - of cultivar L35/11 middle stalwart bewhiskered and cultivar L303/04 semi-dwarf bewhiskered, and maize (Zea mays L.) hybrid Palmyra FAO 190, as well as stimulating cytokinin-like activity of all tested compounds on growth of the isolated cotyledons of pumpkin (Cucurbita moschata Duch. et Poir.) of cultivar Gilea.The activity of tested synthetic low molecular weight heterocyclic compounds derivatives of pyrimidine, pyrazole, and oxazole used at concentration $10^{-9} \mathrm{M} / 1$ of distilled water was similar or higher than activity of phytohormones auxins IAA and NAA, and cytokinin Kinetin used at the same concentration 10${ }^{9} \mathrm{M} / 1$ of distilled water. Study of regulating effect of synthetic heterocyclic compounds derivatives of pyrimidine, pyrazole, and oxazole on photosynthesis in the leaves of pea and maize seedlings showed the positive effect of some from the tested compounds on increase of synthesis of chlorophyll $a$, chlorophyll b, and carotenoids in the plant cells. Based on the obtained results the application in agricultural biotechnology of the most effective from the tested synthetic low molecular weight heterocyclic compounds derivatives of pyrimidine, pyrazole, and oxazole as a new effective substitutes of phytohormones auxins and cytokinins to improve growth and development of pea, maize, and pumpkin is proposed. 


\section{Acknowledgements}

Authors thank to Volkova N.E., Doctor of Biological Sciences, Principal research scientist, Department of General and Molecular Genetics, Plant Breeding \& Genetics Institute - National Center of Seed \& Cultivar Investigation, NAAS, Odessa, Ukraine, for kindly provided seeds of pea (Pisum sativum L.) of cultivars L35/11 middle stalwart bewhiskered and L303/04 semi-dwarf bewhiskered, and maize (Zea mays L.) hybrid Palmyra FAO 190.

\section{References}

[1]. Haughn GW, Somerville CR (1988) Genetic control of morphogenesis in Arabidopsis. Dev Genet. 9(2): 73-89.

[2]. Fosket D (1994) Plant Growth and Development A Molecular Approach. (1st Edtn), Academic Press. 39(2): 580.

[3]. Abid G, Jacquemin J, Sassi K, Muhovski Y, Toussaint A, et al., (2010) Gene expression and genetic analysis during higher plants Embryogenesis. Biotechnol Agron Soc Environ. 14(4): 667-680.

[4]. Tsygankova VA (2015) Genetic Control and Phytohormonal Regulation of Plant Embryogenesis. Int. J Med. Biotechnol. Genetics (IJMBG). 3(1): 9-20.

[5]. Prunet N, Meyerowitz EM (2016) Genetics and plant development. C R Biol. 339(7-8): 240-246.

[6]. Gray WM (2004) Hormonal Regulation of Plant Growth and Development. PLoS Biol. 2(9): e311. doi: 10.1371/journal.pbio.0020311

[7]. Kende H, Zeevaart JAD (1997) The Five Classical Plant Hormones. The Plant Cell. 9(1): 197-121.

[8]. Davies PJ (2004) Plant Hormones - Biosynthesis, Signal Transduction, Action! Kluwer Academic Publ. Dordrecht, Boston, London. 776.

[9]. Hedden P, Thomas SG (2006) Plant Hormone Signaling. Blackwell Publishing Ltd. 339.

[10]. Lam-Son T, Sikander P (2014) Phytohormones: A Window to Metabolism, Signaling and Biotechnological Applications. Springer-Verlag New York. 361.

[11]. Erb M, Glauser G (2010) Family business: multiple members of major phytohormone classes orchestrate plant stress responses. Chemistry. 16(34): 10280-10289. doi: 10.1002/chem.201001219.

[12]. Javid MG, Sorooshzadeh A, Moradi F, Sanavy SAMM, Allahdadi I (2011) The role of phytohormones in alleviating salt stress in crop plants. Australian J Crop Sci. 5(6): 726-734.

[13]. Pieterse CMJ, Vander Does D, Zamioudis C, Leon Reyes A, Van Wees SCM (2012) Hormonal Modulation of Plant Immunity. Annual Review of Cell and Developmental Biology. 28: 489-521.

[14]. Denancé N, Sánchez-Vallet A, Goffner D, Molina A (2013) Disease resistance or growth: the role of plant hormones in balancing immune responses and fitness costs. Front Plant Sci. 4(155): 1-12.

[15]. De Smet S, Cuypers A, Vangronsveld J, Remans T (2015) Gene Networks Involved in Hormonal Control of Root Development in Arabidopsis thaliana: A Framework for Studying Its Disturbance by Metal Stress. Int J Mol Sci. 16: 19195-19224. doi:10.3390/ijms160819195

[16]. Wania SH, Kumarb V, Shriramc V, Sahd SK (2016) Phytohormones and their metabolic engineering for abiotic stress tolerance in crop plants. The crop J. 4: 162-176.

[17]. Rejeb IB, Pastor V, Mauch-Mani B (2014) Plant Responses to Simultaneous Biotic and Abiotic Stress: Molecular Mechanisms. Plants. 3(4): 458-475. doi: $10.3390 /$ plants3040458

[18]. Arteca RN (1996) Plant Growth Substances: Principles and Applications. 1 st (Edn), 332.

[19]. Victoriya A, Tsygankova, Larysa A Galkina, Ludmila I Musatenko, Konstantyn M Sytnik (2005) Genetic and epigenetic control of plant growth and development. Molecular-genetic control of transmission and realization of auxin signals. Biopolym Cell. 21(1): 187-219.

[20]. Victoriya A Tsygankova, Larysa A Galkina, Ludmila I Musatenko, Konstantyn M Sytnik (2005) Genetic and epigenetic control of plant growth and development. Genes of auxin biosynthesis and auxin regulated genes controlling plant cell division and extension. Biopolym Cell. 21(2): 107-133.

[21]. Zhao Yu (2010) Auxin biosynthesis and its role in plant development. Annu Rev Plant Biol. 61: 49-64.

[22]. George EF, Hall MA, De Klerk GJ (2008) Plant Growth Regulators I: Introduction; Auxins, their Analogues and Inhibitors. Plant Propagation by Tissue Culture. (3rd Edn), Springer. 175-204.
[23]. Spartz AK, Gray WM (2008) Plant hormone receptors: new perceptions. Genes \& development. 22(16): 2139-2148.

[24]. Pop TI, Pamfil D, Bellini C (2011) Auxin Control in the Formation of Adventitious Roots. Not Bot Hort Agrobot Cluj. 39(1): 307-316.

[25]. Gao Ya, Zhao Yu (2014) Auxin Biosynthesis and Catabolism. Auxin and Its Role in Plant Development. Springer-Verlag Wien. VII: 444. DOI 10.1007/978-3-7091-1526-8_2.

[26]. Wang YH, Irving HR (2011) Developing a model of plant hormone interactions. Plant Signal Behav. 6(4): 494-500. doi: 10.4161/psb.6.4.14558.

[27]. Rahman A (2013) Auxin: a regulator of cold stress response. Physiol Plant. 147: $28-35$.

[28]. Takatsuka H, Umeda M (2014) Hormonal control of cell division and elongation along differentiation trajectories in roots. J Exp Botany. 65(10): 2633-2643. doi:10.1093/jxb/ert485

[29]. Müller D, Ottoline Leyser O (2011) Auxin, cytokinin and the control of shoot branching(2011). Ann Bot. 107(7): 1203-1212. doi: 10.1093/aob/ mcr069

[30]. Mok DWS, Mok MC (2001) Cytokinin metabolism and action. Annu Rev Plant Physiol Plant Mol Biol. 52: 89-118.

[31]. Haberer G, Kieber JJ (2002) Cytokinins. New Insights into a Classic Phytohormone. Plant Physiol. 128(2): 354-362.

[32]. George EF, Hall MA, De Klerk GJ (2008) Plant Growth Regulators II: Cytokinins, their Analogues and Antagonists. Plant Propagation by Tissue Culture. (3rd Edn), Springer. 205-226.

[33]. Coolbaugh RC (1985) Sites of Gibberellin Biosynthesis in Pea Seedlings. Plant Physiol. 78: 655-657.

[34]. Hedden P (1997) Gibberellin Biosynthesis: Enzymes, Genes and Their Regulation. Annu Rev Plant Physiol Plant Mol Biol. 48: 431-60.

[35]. George EF, Hall MA, De Klerk GJ (2008) Plant Growth Regulators III: Gibberellins, Ethylene, Abscisic Acid, their Analogues and Inhibitors; Miscellaneous Compounds. Plant Propagation by Tissue Culture. (3rd Edn), Springer. 227-281.

[36]. Mutasa-Göttgens E, Hedden P (2009) Gibberellin as a factor in floral regulatory networks. J Exp Botany. 60(7): 1979-1989. doi:10.1093/jxb/erp040.

[37]. Daviére JM, Achard P (2013) Gibberellin signaling in plants. Development. 140(6): 1147-1151. doi:10.1242/dev.087650

[38]. Gupta R, Chakrabarty SK (2013) Gibberellic acid in plant. Plant Signal Behav. 8(9): e25504. DOI: 10.4161/psb.25504

[39]. Finkelstein RR, Gampala SSL, Rock CD (2002) Abscisic Acid Signaling in Seeds and Seedlings. Plant Cell.14: S15-S45.

[40]. Kermode AR (2005) Role of Abscisic Acid in Seed Dormancy. J Plant Growth Regul. 24(4): 319-344. DOI: 10.1007/s00344-005-0110-2

[41]. Nambara E, Okamoto M, Tatematsu K, Yano R, Seo M, (2010) Abscisic acid and the control of seed dormancy and germination. Seed Sci Res. 20(2): 55-67. doi:10.1017/S0960258510000012.

[42]. Tuteja N (2007) Abscisic Acid and Abiotic Stress Signaling. Plant Signal Behav. 2(3): 135-138.

[43]. Beaudoin N, Serizet C, Gosti F, Giraudat J (2000) Interactions between Abscisic Acid and Ethylene Signaling Cascades. Plant Cell. 12(7): 1103-1115.

[44]. Burg SP (1968) Ethylene, Plant Senescence and Abscission. Plant Physiol. 43(9): 1503-1511.

[45]. Saltveit ME (1999) Effect of ethylene on quality of fresh fruits and vegetables. Postharvest Biol Technol. 15: 279-292.

[46]. Cervantes E (2006) Ethylene in Seed Germination and Early Root Development. Floriculture, Ornamental and Plant Biotechnology. Global Science Books. I: 429-438.

[47]. Barry CS, Giovannoni JJ (2007) Ethylene and Fruit Ripening. J Plant Growth Regul. 26(2): 143-159. DOI: 10.1007/s00344-007-9002-y.

[48]. Vandenbussche F, Vaseva I, Vissenberg K, Van Der Straeten D (2012) Ethylene in vegetative development: a tale with a riddle. New Phytol. 194(4): 895-909 doi: 10.1111/j.1469-8137.2012.04100.x.

[49]. Clouse SD (1998) BRASSINOSTEROIDS: Essential Regulators of Plant Growth and Development. Annu Rev Plant Physiol Plant Mol Biol. 49: 427-51.

[50]. Rao SSR, Vardhini BV, Sujatha E, Anuradha S (2002) Brassinosteroids - A new class of phytohormones. Curr sci. 82(10): 1239-1245.

[51]. Zullo MAT, Adam G (2002) Brassinosteroid phytohormones - structure, bioactivity and applications. Braz J Plant Physiol. 14(3): 143-181.

[52]. Hayat S, Ahmad A (2003) Brassinosteroids: Bioactivity and Crop Productivity. Springer Netherlands. XIII: 246. DOI: 10.1007/978-94-017-0948-4.

[53]. Wang ZY, Bai MY, Oh E, Zhu JY (2012) Brassinosteroid Signalling Network and Regulation of Photomorphogenesis. Ann Rev Genet. 46: 701724. DOI: $10.1146 /$ annurev-genet-102209-163450

[54]. Kutschera U, Wang ZY (2012) Darwin review. Brassinosteroid action in flowering plants: a Darwinian Perspective. J Exp Botany. 63(10): 35113522. doi:10.1093/jxb/ers065

[55]. Adam G, Duke SO, Gross D, Lischewski M, Marquardt V, et al., (2012) 
Herbicide Resistance — Brassinosteroids, Gibberellins, Plant Growth Regulators. Chemistry of Plant Protection. 1st (Edn), Springer Berlin Heidelberg. 7: 176.

[56]. Zhu JY, Sae-Seaw J, Wang ZY (2013) Brassinosteroid signalling. Development. 140(8): 1615-1620. doi:10.1242/dev.060590

[57]. Yusuf M, Khan TA, Fariduddin Q (2017) Brassinosteroids: Physiological Roles and its Signalling in Plants. 241-260. Stress Signaling in Plants: Genomics and Proteomics Perspective. Springe. 2: 350. DOI: 10.1007/9783-319-42183-4

[58]. Creelman RA, Mullet JE (1997) Oligosaccharins, brassinolides, and jasmonates: nontraditional regulators of plant growth, development, and gene expression. Plant Cell. 9(7): 1211-1223.

[59]. Tung P, Hooker TS, Tampe PA, Reid DM, Thorpe TA (1996) Jasmonic Acid: Effects on Growth and Development of Isolated Tomato Roots Cultured In vitro. Int J Plant Sci. 157(6): 713-721.

[60]. Creelman RA, Mullet JE (1997) Biosynthesis and action of jasmonates in plants. Annu Rev Plant Physiol Plant Mol Biol. 48: 355-381.

[61]. Lischweski S, Muchow A, Guthörl D, Hause B (2015) Jasmonates act positively in adventitious root formation in petunia cuttings. BMC Plant Biology.15: 229. DOI 10.1186/s12870-015-0615-1.

[62]. Ahmad P, Rasool S, Gul A, Sheikh SA, Akram NA, et al., (2016) Jasmonates: Multifunctional Roles in Stress Tolerance. Front Plant Sci. 7: 813. doi: $10.3389 /$ fpls.2016.00813.

[63]. Vlot AC, Dempsey DA, Klessig DF (2009) Salicylic Acid, a Multifaceted Hormone to Combat Disease. Annu Rev Phytopathol. 47: 177-206.

[64]. Vicente MRS, Plasencia J (2011) Salicylic acid beyond defence: its role in plant growth and development. J Exper Botany. 62(10): 3321-3338. doi:10.1093/jxb/err031.

[65]. Wani AB, Chadar H, Wani AH, Singh S, Upadhyay N (2016) Salicylic acid to decrease plant stress. Environ Chem Lett. DOI 10.1007/s10311016-0584-0

[66]. Phillips P, Khachatourians GG (2001) The Biotechnology Revolution in Global Agriculture: Invention, Innovation and Investment in the Canola Sector. CABI. 360

[67]. Pretty J (2008) Agricultural sustainability: concepts, principles and evidence. Phil Trans R Soc B Bio Sci. 363(1491): 447-465.

[68]. Flynne WG (2008) Biotechnology and Bioengineering. Nova Publishers. 272.

[69]. Kirakosyan A, Kaufman PB (2009) Recent Advances in Plant Biotechnology. Springer Sci Busi media. XVI: 412

[70]. Aerni P (2010) Is agricultural biotechnology part of sustainable agriculture? Different views in Switzerland and New Zealand. Ag Bio Forum. 13(2): 158-172.

[71]. Haggag WM, Abouziena HF, Abd-El-Kreem F, El Habbasha S (2015) Agriculture biotechnology for management of multiple biotic and abiotic environmental stress in crops. J Chemi Pharmac Res. 7(10): 882-889.

[72]. Björnberg KE, Jonas E, Marstorp H, Tidaker P (2015) The Role of Biotechnology in Sustainable Agriculture: Views and Perceptions among Key Actors in the Swedish Food Supply Chain. Sustainability. 7(6): 7512-7529. doi: $10.3390 /$ su7067512

[73]. Qian X, Zhao Z, Xu Y, Xu JH, Zhang YH, et al., (2015) Chemical Biotechnology and Bioengineering (Green Chemistry Series). Royal Society of Chemistry. 234.

[74]. Varshney RK, Dubey AJ (2009) Novel Genomic Tools and Modern Genetic and Breeding Approaches for Crop Improvement. Plant Biochemi Biotechnol. 18(2): 127-138.

[75]. Brummer EC, Barber WT, Collier SM, Cox TS, Johnson R, et al., (2011) Plant breeding for harmony between agriculture and the environment. Front Ecol Environ. 9(10): 561-568.

[76]. New Technologies, Tools and Approaches for Improving Crop Breeding (2012). JIPB. 54(4): 210-214.

[77]. Carlos J, Dias S (2015) Biodiversity and Plant Breeding as Tools for Harmony between Modern Agriculture Production and the Environment. Molecular Approaches to Genetic Diversity. In Tech. 218.

[78]. Al-Khayri JM, Jain SM, Johnson DV (2015) Advances in plant breeding strategies: Breeding, biotechnology and molecular tools, Springer. XII: 707.

[79]. Gaspar T, Kevers C, Penel C, Greppin H, Reid DM, et al., (1996) Plant hormones and plant growth regulators in plant tissue culture. In Vitro Cell Dev Biol Plant. 32(4): 272-289.

[80]. George EF, Hall MA, De Klerk GJ (2008) Plant Propagation by Tissue Culture. The Background, Springer. 1: 501.

[81]. Smith RH (2013) Plant Tissue Culture: Techniques and Experiments. Academic Press. 188.

[82]. Ronald P (2011) Plant Genetics, Sustainable Agriculture and Global Food Security. Genetics. 188(1): 11-20.

[83]. Hilder VA, Boulter D (1999) Genetic engineering of crop plants for insect resistance a critical review. Crop Protection. 18(3): 177-191.
[84]. Ji Q, Xu X, Wang K (2013) Genetic transformation of major cereal crops. Int J Dev Biol. 57(6-8): 495-508. doi: 10.1387/ijdb.130244kw.

[85]. VA Tsygankova, AI Yemets, HO Iutinska, LO Beljavska, AP Galkin, et al., (2013) Increasing the Resistance of Rape Plants to the Parasitic Nematode Heterodera schachtii Using RNAi Technology. Cytology and Genetics. 47(4): 222-230.

[86]. Basra AS (2000) Plant Growth Regulators in Agriculture and Horticulture: Their Role and Commercial Uses. Haworth Press, Inc., New York, London, Oxford. 264.

[87]. Ferguson L, Lessenger JE (2006) Plant Growth Regulators. Agricultural Medicine - A Practical Guide. Springer Science Business Media. 156-166.

[88]. Rademacher W (2015) Plant Growth Regulators: Backgrounds and Uses in Plant Production. J Plant Growth Regul. 34(4): 845 - 872

[89]. Meena OP (2015) A Review: role of plant growth regulators in vegetable production. Int J Agricul Sci Res. IJASR. 5(5): 71-84.

[90]. Lopez-Lauri F (2016) Plant Growth Regulators. Postharvest Management Approaches for Maintaining Quality of Fresh Produce. Springer Intl Publ Switzerland. 222: 125-139.

[91]. Victoria Tsygankova, Elena Shysha, Yaroslav Andrusevich, Anatoly Galkin, Galina Iutynska, et al., (2016) Using of new microbial biostimulants for obtaining in vitro new lines of Triticum aestivum L. cells resistant to nematode H. avenae. Eur J Biotechnol Biosci. 4(4): 41-53.

[92]. Calvo P, Nelson L, Kloepper JW (2014) Agricultural uses of plant biostimulants. Plant Soil. 383(1): 3-41. DOI 10.1007/s11104-014-2131-8.

[93]. Jardin P (2015) Plant biostimulants: Definition, concept, main categories and regulation. Sci Hortic. 196(30): 3-14.

[94]. Le Mire G, Nguyen ML, Fassotte B, Jardin P, Verheggen F, et al., (2016) Implementing plant biostimulants and biocontrol strategies in the agroecological management of cultivated ecosystems. A review Biotechnol Agron Soc Environ. 20(S1): 299- 313.

[95]. Joule JA, Mills K (2012) Heterocyclic Chemistry at a Glance. (2nd edn), John Wiley \& Sons, Ltd. 230.

[96]. Quin LD, Tyrell JA (2010) Fundamentals of heterocyclic chemistry: Importance in Nature and in the Synthesis of Pharmaceuticals. John Wiley \& Sons, Hoboken, New Jersey. 344.

[97]. Scriven EFV, Murugan R (2005) Pyridine and Pyridine Derivatives. KirkOthmer Encyclopedia of Chemical Technology. John Wiley \& Sons, Inc. 20: $1-53$.

[98]. Brown DJ (2007) The Chemistry of Heterocyclic Compounds. The Pyrimidines, Wiley-Interscience. 16: 774

[99]. Cansev A, Gulen H, Kesici, M, Ergin S, Cansev M, et al., (2016) Use of pyrimidines in stimulation of plant growth and development and enhancement of stress tolerance. Patent. 20160000075.

[100]. Miller MJ, Moraski GC, Markley LD, Davis GE (2012) Imidazo [1,2-a] pyridine compounds, synthesis thereof, and methods of using same. Patent US. 20120220457 A1.

[101]. Nimbalkar S, Hote SV (2015) Pyrazole Derivatives and their Synthesis - A review. Intl J Recent Innovation Trend Comput Comm. 3(2): 61-65.

[102]. Baum JS, Chen TM (1987) Plant growth and development modification using benzoxazole derivatives. Patent US 4659360 A.

[103]. Chang JH, Baum JS (1990) Phenylmethyl-4, 4-dimethyl-3-isoxazolidinone plant regulators. Patent US 4892578 A.

104]. Newton T, Waldeck I (2000) Oxazole carboxamide herbicides. Patent US6096688 A.

[105]. Dai H, Li YQ, Du D, Qin X, Zhang X, Yu HB, et al., (2008) Synthesis and biological activities of novel pyrazole oxime derivatives containing a 2-chloro-5-thiazolyl moiety. J Agric Food Chem. 56(22): 10805-10810.

[106].Zhao Q, Liu Sh, Li Yo, Wang Q (2009) Design, Synthesis, and Biological Activities of Novel 2-Cyanoacrylates Containing Oxazole, Oxadiazole, or Quinoline Moieties. J Agric Food Chem. 57(7): 2849-2855.

[107].Corsi C, Wendeborn SV, Bobbio C, Kessabi J, Schneiter P, et al., (2011) Isothiazole and pyrazole derivatives for use as plant growth regulators. EP Patent 2358699A1.

[108].Xiao Sh, Guo D, Zhang M, Peng Sh, Chen F, et al., (2016) Two novel 2,5-diphenyl oxazole derivatives from Gymnotheca chinensis Chin. Chem Lett. 27(7): 1064-1066

[109]. Preedy VR (2013) Isoflavones: Chemistry, Analysis, Function and Effects. CPI Group8 Ltd, Croydon, CR0 4YY, UK. 683.

[110].Sergiev I, Alexieva V, Ivanov S, Bankova V, Mapelli S (2004) Plant Growth Regulating Activity of Some Flavonoids. Comptes rendus of the Bulgarian academy of sciences. 57(4): 63-68

[111]. Karkanis A, Ntatsi G, Kontopoulou CK, Pristeri A, Bilalis D, et al., (2016) Field Pea in European Cropping Systems: Adaptability, Biological Nitrogen Fixation and Cultivation Practices. Not Bot Horti Agrobo. 44(2): 325-336.

[112].Zahran HH (1999) Rhizobium-Legume Symbiosis and Nitrogen Fixation under Severe Conditions and in an Arid Climate. Microbiol Mol Biol Rev. 63(4): 968-989. 
[113]. Murcia M A, Rincón F (1991) Fatty acid composition of pea (Pisum sativum L., var. Citrina) during seed growth. Grasas y Aceites. 42(6): 444-449.

[114]. Campos-Vega R, Loarca-Piña G, Oomah BD (2010) Minor components of pulses and their potential impact on human health. Food Res Intl. 43: 461-482.

[115]. Dahl WJ, Foster LM, Tyler RT (2012) Review of the health benefits of peas (Pisum sativum L.). Br J Nutr. 108: S3-S10. doi:10.1017/ S0007114512000852

[116]. Clemente A, Carmen Marín-Manzano M, Jiménez E, Carmen Arques M (2012) The anti-proliferative effect of TI1B, a major Bowman-Birk isoinhibitor from pea (Pisum sativum L.), on HT29 colon cancer cells is mediated through protease inhibition. Br J Nutrition. 108(1): S135-S144. doi:10.1017/S000711451200075X.

[117]. Rubio LA, Pérez A, Ruiz R, Guzmán MA, Aranda-Olmedo I, et al., (2014) Characterization of pea (Pisum sativum) seed protein fractions. J Sci Food Agric. 94(2): 280-287. DOI:10.1002/jsfa.6250

[118]. Meisrimler CN, Menckhoff L, Kukavica BM, Lüthje S (2015) Pre-fractionation strategies to resolve pea (Pisum sativum) sub-proteomes. Front Plant Sci. 6: 849. doi: 10.3389/fpls.2015.00849

[119]. Ferraro K, Jin AL, Nguyen TD, Reinecke DM, Ozga JA, et al., (2014) Characterization of proanthocyanidin metabolism in pea (Pisum sativum) seeds. BMC Plant Biology. 14: 238.

[120]. Milind P, Isha D (2013) Zea maize: a modern craze. Int Res J Pharm. 4(6): 39-43.

[121]. Shah TR, Prasad K, Kumar P (2016) Maize-A potential source of human nutrition and health: A review. Cogent Food Agricul. 2(1): 1166995.

[122]. Barros M, Fleuri LF, Macedo GA (2010) Seed lipases: sources, applications and properties - A review. Braz J Chemi Eng. 27(1): 15-29.

[123]. Oksana S, Marian B, Mahendra R, Bo SH (2012) Plant phenolic compounds for food, pharmaceutical and cosmetics production. J Med Plants Res. 6(13): 2526-2539.

[124]. Pimentel D, Patzek TW (2005) Ethanol Production Using Corn, Switchgrass, and Wood; Biodiesel Production Using Soybean and Sunflower. Nat Resour Res. 14(1): 65-76.

[125]. Dhugga KS (2007) Maize Biomass Yield and Composition for Biofuels. Crop Sci. 47(6): 2211-2227.

[126]. Kanengoni AT, Chimonyo M, Ndimba BK, Dzama K (2015) Potential of Using Maize Cobs in Pig Diets - A Review. Asian Australas J Anim Sci. 28(12): 1669-1679.

[127].Donkoh A, Nyannor EKD, Asafu-Adjaye A, Duah J (2003) Ground maize cob as a dietary ingredient for broiler chickens in the tropics. J Animal Feed Sci. 12: 153-161.

[128]. Stevenson D, Eller F, Wang L, Jane J, Wang T, et al., (2007) Oil and tocopherol content and composition of pumpkin seed oil in 12 cultivars. J Agric Food Chem. 55(10): 4005-4013. DOI: 10.1021/jf0706979.

[129]. Elhardallou SB, Elawad AM, Khairi NA, Gobouri AB, Dhahawi HO (2014) A Review on Omega-3 and Omega-6 Essential Fatty Acids: Uses, Benefits and their Availability in Pumpkins (Cucurbita maxima) Seed and Desert Dates (Balanites aegyptiaca) Seed Kernel Oils. Pak J Biol Sci. 17(12): 1195-1208. DOI: 10.3923/pjbs.2014.1195.1208.

[130]. Habib A, Biswas S, Siddique AH, Manirujjaman M, Uddin B, et al., (2015) Nutritional and Lipid Composition Analysis of Pumpkin Seed (Cucurbita maxima Linn.). J Nutr Food Sci. 5: 374. doi:10.4172/2155-9600.1000374.

[131]. Procida G, Stancher B, Cateni F, Zacchigna M (2013) Chemical composition and functional characterisation of commercial pumpkin seed oil. J Sci Food Agric. 93(5): 1035-41. doi: 10.1002/jsfa.5843.

[132]. Muruganantham N, Solomon S, Senthamilselvi MM (2016) Antimicrobial activity of Cucurbita maxima flowers (Pumpkin). J Pharmacognosy Phytochemistry. 5(1): 15-18

[133]. Bardaa S, Halima N, Aloui F, Mansour R, Jabeur H, et al., (2016) Oil from pumpkin (Cucurbita pepo L.) seeds: evaluation of its functional properties on wound healing in rats. Lipids Health Dis. 15: 73. doi: 10.1186/s12944016-0237-0.

[134]. Baumgartner S, Thurneysen A, Heusser P (2004) Growth stimulation of dwarf peas (Pisum sativum L.) through homeopathic potencies of plant growth substances. Forsch Komplementarmed Klass Naturheilkd. 11(5): 281-92.

[135]. Baumgartner S, Shah D, Schaller J, Kämpfer U, Thurneysen A, et al., (2008) Reproducibility of dwarf pea shoot growth stimulation by homeopathic potencies of gibberellic acid. Complement Ther Med. 16(4): 183-191. DOI: 10.1016/j.ctim.2008.03.001

[136]. Thomson T, Patel GS, Pandya KS, Dabhi JS, Pawar Y (2015) Effect of plant growth substances and antioxidants on growth, flowering, yield and economics of garden pea, Pisum sativum L cv Bonneville. Int J Farm Sci. 5(1): $8-13$.

[137].Abd El-Wahed MSA, Amin AA, Rashad El-ShM (2006) Physiological effect of some bioregulators on vegetative growth yield and chemical constituents of yellow maize plants. World J Agricultural Sciences. 2(2): 149-155.

[138]. Kaya C, Tuna AL, Okan AM (2010) Effect of foliar applied kinetin and indole acetic acid on maize plants grown under saline conditions. Turk J Agric For. 34: 529-538.

[139]. Ghodrat V, Rousta MJ (2012) Effect of Priming with Gibberellic Acid (GA3) on Germination and Growth of Corn (Zea mays L.) under Saline Conditions. Intl J Agri Crop Sci. 4(13): 882-885.

[140]. Ghodrat V, Rousta MJ, Tadaion MS, Karampour A (2012) Yield and Yield Components of Corn (Zea mays L.) In Response to Foliar Application with Indole Butyric Acid and Gibberellic Acid. American-Eurasian J Agric \& Environ Sci. 12(9): 1246-1251.

[141].Amin AA, Abd El-Kader AA, Shalaby MAF, Gharib FAE, Rashad El-S M, et al., (2013) Physiological Effects of Salicylic Acid and Thiourea on Growth and Productivity of Maize Plants in Sandy Soil. Commun Soil Sci Plant Analy. 44(7): 1141-1155.

[142]. Rashad RT, Hussien RA (2014) A comparison study on the effect of some growth regulators on the nutrients content of maize plant under salinity conditions. Ann Agricul Sci. 59(1): 89-94.

[143]. Noureddini M, Sharafzadeh SH (2014) Impact of foliar application of salicylic acid on growth, yield and yield components of maize plants. IJBPAS. 3(5): 686-693.

[144]. Abdelgawad ZA, Khalafaallah AA, Abdallah MM (2014) Impact of Methyl Jasmonate on Antioxidant Activity and Some Biochemical Aspects of Maize Plant Grown under Water Stress Condition. Agricul Sci. 5(12): 1077-1088.

[145]. Abd El-Samad HM, Shaddad MAK (2014) The Exogenous Amelioration Roles of Growth Regulators on Crop Plants Grow under Different Osmotic Potential. J Stress Physiol Biochem. 10(1): 203-213.

[146].Spitzer T, Míša P, Bílovský J, Kazda J (2015) Management of Maize Stand Height using Growth Regulators. Plant Protect Sci. 51(4): 223-230.

[147]. Wang Y, Gu W, Xie T, Li L, Sun Y, et al., (2016) Mixed Compound of DCPTA and CCC Increases Maize Yield by Improving Plant Morphology and Up-Regulating Photosynthetic Capacity and Antioxidants. PLoS one. 11(2): e0149404.

148]. Pricinotto LF, Zucareli C, Fonseca ICB, Oliveira MA, Ferreira AS, et al., (2015) Trinexapac-ethyl in the vegetative and reproductive performance of corn. Afr j Agricul Res. 10(14): 1735-1742.

[149]. Sedghi M, Gholipouri A, Sharif RS (2008) Gama-Tocopherol Accumulation and Floral Differentiation of Medicinal Pumpkin (Cucurbita pepo L.) in Response to Plant Growth Regulators. Not Bot Hort Agrobot Cluj. 36(1): 80-84.

[150].El Shora HM, Ali AS (2016) Plant growth regulators induced urease activity in Cucurbita pepo L. cotyledons. Acta Biol Hung. 67(1): 53-63. doi: 10.1556/018.67.2016.1.4

[151]. Victoria Tsygankova, Yaroslav Andrusevich, Olexandra Shtompel, Artem Hurenko, Roman Solomyannyj, et al., (2016) Stimulating effect of five and six-membered heterocyclic compounds on seed germination and vegetative growth of maize(Zea mays L). Int J Biol Res. 1(4): 1-14.

[152]. Victoria Tsygankova, Yaroslav Andrusevich, Olexandra Shtompel, Stepan Pilyo, Volodymyr Prokopenko, et al., (2016) study of growth activity derivatives of $[1,3]$ Oxazolo[5,4-d] pyrimidine and N-Sulfonyl substituted of 1,3-Oxazole on soybean, wheat, flax and pumpkin plants. Int J Chemi Stud. 4(5): 106-120.

[153]. Victoria Tsygankova, Yaroslav Andrusevich, Olexandra Shtompel, Olexandr Myroljubov, Artem Hurenko, et al., (2016) Study of Auxin, Cytokinin and Gibberellin-like Activity of Heterocyclic Compounds Derivatives of Pyrimidine, Pyridine, Pyrazole and Isoflavones. Eur J Biotechnol Biosci. 4(12): $29-44$.

[154]. Tsygankova VA, Bayer OO, Andrusevich YaV, Galkin AP, Brovarets VS, Yemets AI, Blume YaB (2016) Screening of five and six-membered nitrogen-containing heterocyclic compounds as new effective stimulants of Linumusitatissimum L. organogenesis in vitro. Int J Med Biotechnol Genetics. S2: 001, 1-9.

[155]. Voytsehovska OV, Kapustyan AV, Kosik OI, Musienko MM, Olkhovich OP, Panyuta OO, et al., (2010) Plant Physiology: Praktykum. Lutsk: Teren. 420.

[156]. Gyulai G, Heszky LE (1995) Auxin and cytokinin bioassays: a short overview. Acta Agronomica Hungarica. 43(1/2): 185-197.

[157]. Chen CM, Leisner SM (1985) Cytokinin-Modulated Gene Expression in Excised Pumpkin. Plant Physiol. 77(1): 99-103.

[158]. Lichtenthaler HK (1987) Chlorophylls and carotenoids: Pigments of photosynthetic biomembranes. Methods in Enzymology. 148: 350-382.

[159]. Bang H, Zhou XK, vanEpps HL, Mazumdar M (2010) Statistical Methods in Molecular Biology. Series: Methods in molecular biology. 13(620): 636.

[160]. Lodish H, Berk A, Zipursky SL (2000) Molecular Cell Biology. (4th Edn), Section 16.3, Photosynthetic Stages and Light-Absorbing Pigments.

[161].Sims DA, Gamon JA (2002) Relationships between leaf pigment content and spectral reflectance across a wide range of species, leaf structures and developmental stages. Remote Sensing Environment. 81(2-3): 337-354. 
[162]. Gratani L (2014) Plant Phenotypic Plasticity in Response to Environmental Factors. Advances in Botany. 208747: 17.

[163]. Bartley GE, Scolnik PA (1995) Plant Carotenoids: Pigments for Photoprotection, Visual Attraction, and Human Health. Plant Cell. 7: 1027-1038.

[164]. Cazzonelli CI (2011) Carotenoids in nature: insights from plants and beyond. Functional Plant Biol. 38: 833-847.

[165]. Eldahshan OA, Singa ANB (2013) Carotenoids. J Pharmacognosy Phytochemistry. 2(1): 225-234.

[166]. Basu RN (1972) Effect of non-auxin chemicals on translocation of auxins in cuttings of Phaseolus vulgaris (L.) (kidney beans). J Exp Bot. 23(2): 357365.

[167]. Oshkaya VP, Mutsenietse DK (1973) Effect of indan-1,3-dione derivatives on root formation in bean cuttings. Soviet Plant Physiol. 21(1): 172-173.

[168]. Pandey A, Tamta S, Giri D (2011) Role of auxin on adventitious root formation and subsequent growth of cutting raised plantlets of Ginkgo biloba L. Intl J Biodiv Conserv. 3(4): 142-146.

[169]. Shimelis D, Bantte K, Feyissa T (2015) Interaction Effect of Indole-3-Butyric Acid and $\alpha$-Naphthalene Acetic Acid on In Vitro Rooting of Two Sugarcane (Saccharum officinarum) Genotypes. Adv Crop Sci Tech. S1: 001. doi:10.4172/2329-8863.S1-001.

[170].Šimonová E, Henselová M, Zahradník P (2005) Benzothiazole derivatives substituted in position 2 as biologically active substances with plant growth regulation activity. Plant Soil Environ. 51(11): 496-505.

[171]. Wilcox EJ, Selby C, Wain RL (1981) The cytokinin activities of 6- $\alpha$-alkylbenzyloxypurines. Ann Appl Biol. 97: 221-226.

[172]. Frankland B, Wareing PF (1960) Effect of gibberellic acid on hypocotyl growth of lettuce seedlings. Nature. 185: 255-256

[173]. Hendrx SD Jones RL (1972) The Activity of beta-Ecdysone in Four Gibberellin Bioassays. Plant Physiol. 50: 199-200.

[174]. Koda Y, Haga T, Okazawa Y (1979) A revised method of gibberellin assay by oat endosperm tissues. J Fac. Agr. Hokkaido Univ. 59(2): 254-261.

[175]. Waycott W, Taiz L (1991) Phenotypic Characterization of Lettuce Dwarf Mutants and Their Response to Applied Gibberellins. Plant Physiol. 95(4): 1162-1168.

[176]. Pattabi V (1990) Plant growth regulators - their structure and interactions.
Current science. 59(23): 1228-1235.

[177]. Kopernik IM, Blagodatnyj VM, Petrenko OV, Kalashnikova LE, Prokopenko VV, et al.,(2011) Study in vitro for antimicrobic activity of new oxazole derivatives and products of its transformations. Ukr Bioorg Acta. 2: 57-68).

[178]. Havrylyuk D, Zimenkovsky B, Vasylenko O, Gzella A, Lesyk R (2012) Synthesis of New 4-Thiazolidinone-, Pyrazoline-, and Isatin-Based Conjugates with Promising Antitumor Activity. J Med Chem. 55(20):8630-8641.

[179].Zelisko N, Atamanyuk D, Vasylenko O, Grellier P, Lesyk R (2012) Synthesis and antitrypanosonal activity of new 6,6,7-trisubstituted thiopyrano[2,3d]-[1,3]thiazoles. Bioorg Med Chem Lett. 22(23): 7071-7074.

[180]. Havrylyuk D, Zimenkovsky B, Vasylenko A, Day GW, Smee DF, et al., (2013) Synthesis and biological activity evaluation of 5-pyrazoline substituted 4-thiazolidinones. Eur J Medi Chemi. 66: 228-237.

[181]. Frasinyuk MS, Mrug GP, Bondarenko SP, Khilya VP, Brovarets VS (2013) Antitumor activity of flavonoid Mannich bases. Ukr Bioorg Acta. 2: 3-7.

[182]. Diopan V, Adam V, Havel L, Kizek R (2009) Phytohormones as Important Biologically Active Molecules - Their Simple Simultaneous Detection. Molecu. 14: 1825-1839. doi:10.3390/molecules14051825.

[183]. Sauer M, Robert S, Kleine-Vehn J (2013) Auxin: simply complicated. J Exper Botany. 64(9): 2565-2577. doi:10.1093/jxb/ert139.

[184]. Rigal A, Ma Q, Robert S (2014) Unraveling plant hormone signaling through the use of small molecules. Front Plant Sci. 373: 1-20.

Special Issue on
"Plant Biology and Genetics"
Edited by:
Victoria Tsygankova ScD,
National Academy of Sciences of
Ukraine (NAS of Ukraine), Ukraine
Email : v'Tsygankova@ukr.net

